Bundesgesundheitsbl -

Gesundheitsforsch - Gesundheitsschutz

2000 • 43:969-993 (c) Springer-Verlag 2000
Tagungsberichte

U.Marcus

Robert Koch-Institut, Berlin

\section{Bericht über die 13. Welt- AIDS-Konferenz in Durban, Südafrika, Juli 2000}

\section{Teil 1: Ein Kontinent schlittert in die Katastrophe - AIDS in Afrika}

\section{Epidemiologie von HIV und AIDS weltweit}

Internationalen AIDS-Konferenz in Durban liegt darin, dass sie die dramatische Entwicklung der AIDS-Epidemie in Schwarzafrika und die schreienden Ungerechtigkeiten beim Zugang zu den Früchten von fast zwei Dekaden AIDSForschung den Teilnehmern und der Weltöffentlichkeit unmissverständlich vor Augen geführt hat. In Vancouver und Genf war es noch möglich, angesichts fehlenden Zugangs zu Therapiemöglichkeiten für die Dritte Welt und angesichts erschreckender, aber anonym bleibender Zahlen die Achseln zu zucken - zu Gast in Durban und unmittelbar konfrontiert mit den Menschen, unter denen den Prognosen der Epidemiologen nach in den kommenden Jahren jeder zweite junge Erwachsene AIDS zum Opfer fallen wird, können nur noch die hartgesottensten Zyniker behaupten, wir könnten so weitermachen wie bisher. Die Konferenz von Durban kann und muss zu einem Wendepunkt im Umgang mit dem Problem AIDS in der Dritten Welt werden. Es war höchste Zeit, dass eine Internationale AIDS-Konferenz in einem afrikanischen Land stattfand. Südafrika eignete sich ganz besonders als Austragungsort, weil sich dort die weltweiten Probleme, Konflikte und Ungerechtigkeiten im Umgang mit dem Problem AIDS wie in einem Mikrokosmos widerspiegeln.
Ende 1999 lebten weltweit etwa 34,3 Millionen Menschen mit einer HIV-Infektion. Zur regionalen Verteilung siehe Abb. $1.71 \%$ der HIV-Infizierten leben in Schwarzafrika, $16 \%$ in Süd- und Südostasien, $7 \%$ in Amerika, 2,7\% in Europa.
Während in der nördlichen Hemisphäre der Anteil der männlichen Infizierten noch deutlich höher ist als der der weiblichen, ist das Geschlechterverhältnis vor allem in Afrika nahezu 1:1. Durch das zahlenmäßige Überwiegen und die raschere Dynamik der Epidemie in Ländern mit vorwiegend heterosexueller Ausbreitung von HIV erreicht der

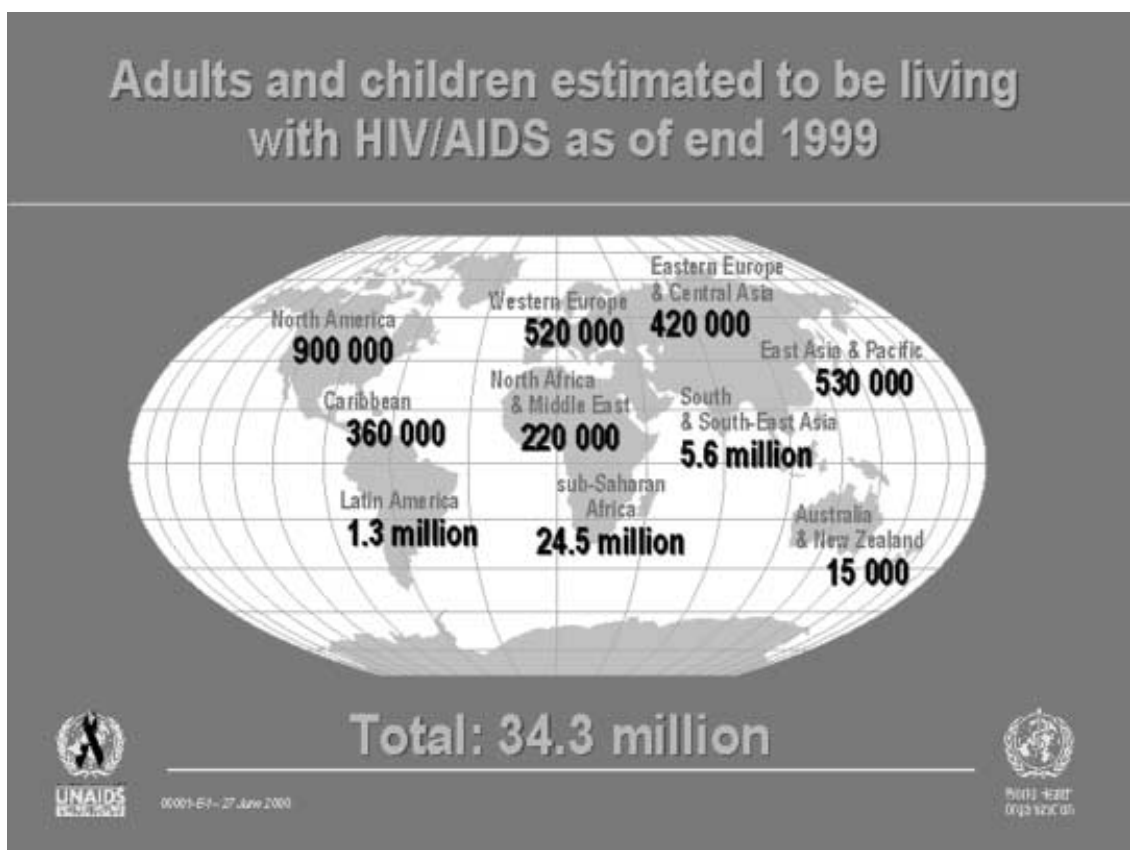

Abb. $1 \Delta$ Weltweite Verteilung der derzeit lebenden ca. 34,3 Millionen HIV-Infizierten (Quelle: UNAIDS) 
Anteil der Frauen an den HIV-Infizierten weltweit nahezu 50\% (15,7 Mio. von 34,3 Mio.). Da Maßnahmen zur Reduktion der Mutter-Kind-Übertragung bislang nur in den Industriestaaten und wenigen Pilotprojekten in Entwicklungsländern angewendet werden, konzentriert sich auch der Löwenanteil der HIV-infizierten Kinder in Entwicklungsländern, v. a. in Schwarzafrika.

Noch deutlicher werden die Unterschiede zwischen Nord und Süd, wenn man die Zahl der Neuinfektionen betrachtet. Weltweit wird deren Zahl für das Jahr 1999 auf ca. 5,4 Millionen geschätzt. Zur regionalen Verteilung siehe Abb. 2. Gerade einmal 1,4\% der Neuinfektionen entfallen auf die entwickelten Industriestaaten in Nordamerika und Westeuropa. Von den 620.000 Neuinfektionen bei Kindern fanden allein $84 \%$ in Schwarzafrika statt.

Am schnellsten wächst die Epidemie in Afrika nach wie vor im Süden und Osten des Kontinents, obwohl diese Regionen bereits bisher die Hauptlast der Epidemie getragen haben. In Westafrika verläuft die Entwicklung insgesamt etwas langsamer. So stieg in Nigeria die landesweit registrierte HIVPrävalenz von 0,9\% im Jahre 1990 auf $5,8 \%$ im Jahre 1999 (in Südafrika war zum Vergleich der Anstieg im selben Zeitraum viermal so schnell). Da Nige- ria aber das bevölkerungsreichste Land Afrikas ist, dürfte die absolute Zahl der HIV-Infizierten mit ca. 5 Millionen mittlerweile sogar höher sein als die Südafrikas (ca. 4,2 Millionen) [Onuwekje et al., MoPeC2459].

\section{"Die Entwicklungen in Indien und China sind von entschei- dender Bedeutung für die weitere Entwicklung der HIV-Epidemie in Asien."}

Von entscheidender Bedeutung für die weitere Entwicklung der HIV-Epidemie in Asien sind die Entwicklungen in den beiden bevölkerungsreichsten Ländern der Welt, Indien und China. Beide Länder befinden sich an der Schwelle zu generalisierten Epidemien. Nach offiziellen Angaben der indischen Nationalen AIDS-Kontrollbehörde NACO liegt die HIV-Prävalenz in der erwachsenen Bevölkerung bereits in sechs von 32 Bundesstaaten höher als $1 \%$, in sieben weiteren liegt die HIV-Prävalenz bei STDPat. bereits über 5\%. Die Gesamtzahl der HIV-Infizierten müsste demnach mindestens 3,5 Millionen betragen [Shaukat, $\mathrm{MoPeC} 2416]$. In Wirklichkeit ist die Situation noch ernster, wie die NACO jüngst selbst zugeben musste. In den

\section{Estimated number of adults and children newly infected with HIV during 1999}

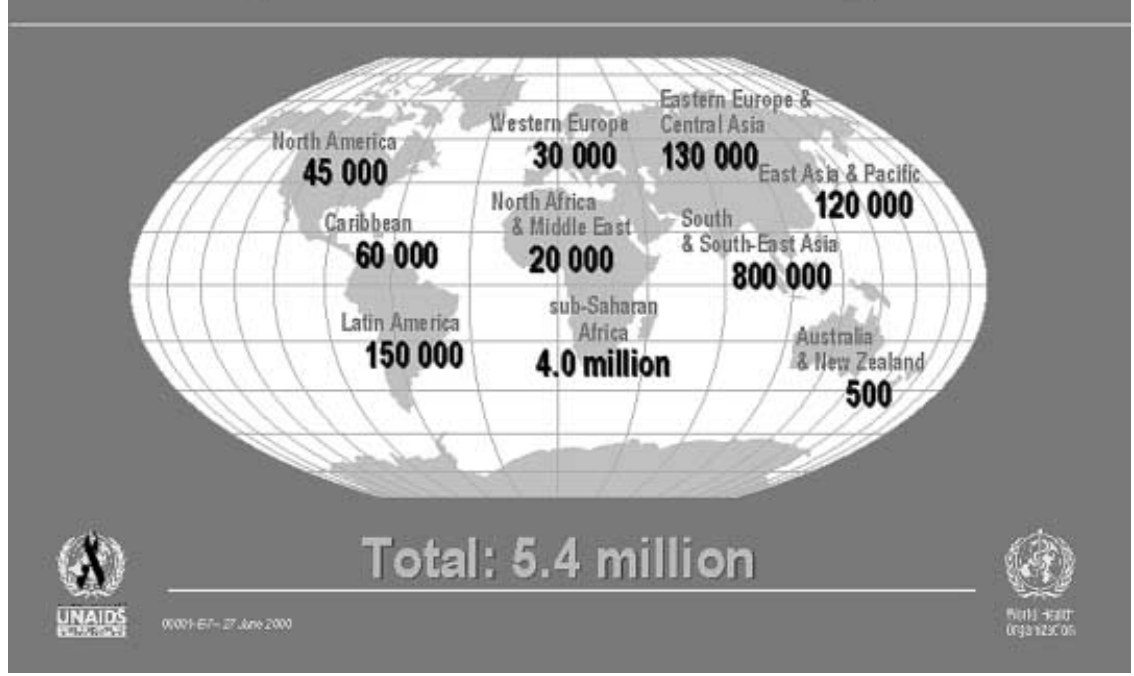

Abb. $2 \triangle$ Weltweite Verteilung der HIV-Neuinfektionen im Jahr 1999 (Quelle: UNAIDS)

drei Bundesstaaten Kerala, Punjab und Westbengalen ist in den vergangenen zwei bis vier Jahren nach den offiziellen Zahlen keine einzige neue HIV-Infektion entdeckt worden - eine Angabe, über die Ärzte aus diesen Regionen nur den Kopf schütteln können [1].

Das in China seit Mitte der neunziger Jahre aufgebaute HIV-Surveillancesystem registrierte 1995 in den damals acht Überwachungspunkten für Drogengebraucher noch keine HIV-Infektionen. 1998 waren Drogengebraucher in 17 von 19 Überwachungspunkten HIV-positiv. In Urumtschi war die HIV-Prävalenz unter i.v.-Drogenkonsumenten zwischen 1995 und 1998 von auf $28,8 \%$ gestiegen, in Guangxi und Guangdong innerhalb eines Jahres von $1 \%$ im Jahre 1997 auf 12,8 bzw. 10,4\% im Jahre 1998. In der Stadt Yining wurde mit $82,2 \%$ die höchste HIV-Prävalenzrate unter Drogengebrauchern in China registriert. Ein Anstieg der HIV-Prävalenz war auch zu beobachten unter Prostituierten und $\mathrm{Pa}$ tienten mit anderen sexuell übertragbaren Infektionen [Qu et al., MoPeC2379] - bislang noch auf relativ niedrigem Niveau. Jedoch steigt die Zahl der STDs in den vergangenen Jahren kontinuierlich an, allein die gemeldeten Fälle haben sich in den vergangenen zwei Jahren verdoppelt (siehe Abb. 3), die Dunkelziffer der im Privatsektor behandelten Fälle wird auf das drei- bis fünffache geschätzt. Ursache hierfür ist $u$. a. die zunehmende Binnenmigration: Zig Millionen von Bauern und Arbeitern konkursgegangener Staatsbetriebe aus den ländlichen Regionen strömen auf Arbeitssuche in die wirtschaftlich florierenden Küstenregionen, in denen die kommerzielle Prostitution aufblüht. Damit sind die Voraussetzungen auch für eine sexuelle Ausbreitung von HIV gegeben.

\section{"In China wird bis zum Jahr 2010 mit einer Gesamtzahl von 10 Millionen HIV-Infizierten gerechnet."}

Das staatliche Nationale Zentrum für AIDS-Prävention und -Kontrolle schätzt die aktuelle Zahl der HIV-Infizierten landesweit auf über 500.000 und befürchtet, falls sich der bisherige Trend ungebrochen fortsetzt, bis zum Jahr 2010 eine Gesamtzahl von 10 Millionen HIV- 


\section{Reported incidence of syphilis and gonorrhoea in China, 1989 to 1998}

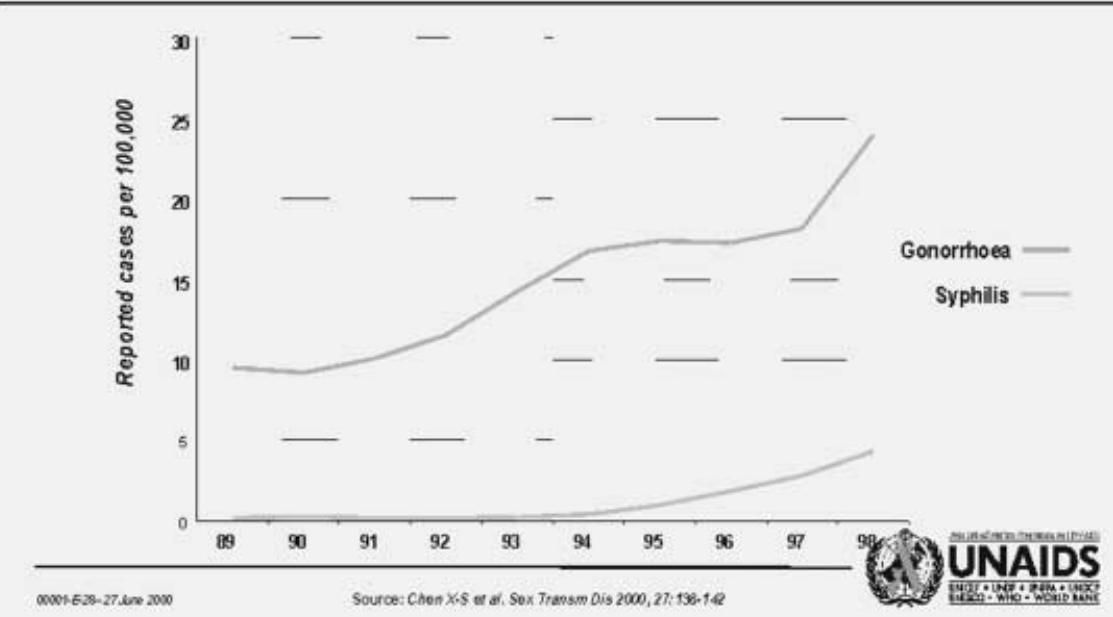

Abb. $3 \Delta$ Zeitliche Entwicklung der offiziell registrierten Gonorrhoe- und Syphilisinzidenz in China in den neunziger Jahren

Infizierten. Die anfänglich sehr zögerliche Regierung beginnt langsam, das Problem ernster zu nehmen. Noch ist das nationale Budget für HIV-Prävention mit 1,75 Mio. US\$ völlig unzureichend, aber bereits für das nächste Jahr wird eine deutliche Steigerung erwartet. Noch wichtiger aber wäre es, wenn die Regierung sich dazu aufraffen könnte, unflexible und dogmatische Positionen abzulegen: Nadelaustauschprogramme und Kondomverteilung an Prostituierte werden offiziell bislang nicht geduldet, weil dies in den Augen der Regierung einem Gutheissen illegaler Tätigkeiten gleichkäme [2].

In Europa übersteigt derzeit die Zahl der HIV-Infizierten mit 520.000 (Stand 1999) in Westeuropa noch die Zahl der Infizierten in Osteuropa (420.000). Bei der gegenwärtigen Dynamik könnte Osteuropa den Westen des Kontinents jedoch bereits in diesem Jahr überholen. Während die Zahl der HIVNeuinfektionen in Westeuropa im Jahre 1999 etwa 30.000 betrug, stieg sie in Osteuropa auf 130.000 an. Besonders schnell wächst die Epidemie derzeit in Russland. 1996 wurden dort noch landesweit 1546 Infektionen neu diagnostiziert, bis 1999 hatte sich die Zahl der jährlichen Neudiagnosen bereits auf 15.462 verzehnfacht und bis Juli 2000 waren bereits 20.526 HIV-Infektionen neu entdeckt worden. (siehe Abb. 4) fektionen. Von 11\% in 1997 stieg er auf $18 \%$ in 1999 [Shcherbinska et al., MoPeC2458]. Dies kommt nicht völlig überraschend, sind doch die Infizierten überwiegend sehr jung, $\sim 60 \%$ sind unter 25 Jahre, und damit der sexuell aktivsten Bevölkerungsgruppe zuzuordnen.

Russische Experten erwarten einen Anstieg der Gesamtzahl der HIV-Infizierten in den kommenden zwei Jahren auf über eine Million. Sie scheinen dann, einigen Äußerungen zufolge, eine Abschwächung der Epidemie zu erwarten, in der Hoffnung, einen "Sättigungswert" ähnlich wie in den USA zu erreichen. Man kann nur hoffen, dass sie sich darin nicht täuschen: im Unterschied zu den USA, wo in den achtziger Jahren verstärkt durch die einsetzende massive AIDS-Prävention die Inzidenz sexuell übertragbarer Infektionen deutlich zurückging, ist der Trend in Russland eher gegenläufig: Go- und Syphilisinzidenzen sind in den vergangenen Jahren kontinuierlich gestiegen (siehe Abb. 5) - angesichts der Kofaktorenrolle, die diese Infektionen für die HIV-Übertragung haben kein besonders ermutigendes Zeichen. Außerdem hat in den vergangenen Jahren auch die Zahl der i.v.-Drogenkonsumenten stark zugenommen. Während in Zentraleuropa schätzungsweise weniger als $0,2 \%$ der Bevölkerung

\section{Annual number of newly registered HIV infections, Russia, 1993 to 1999}

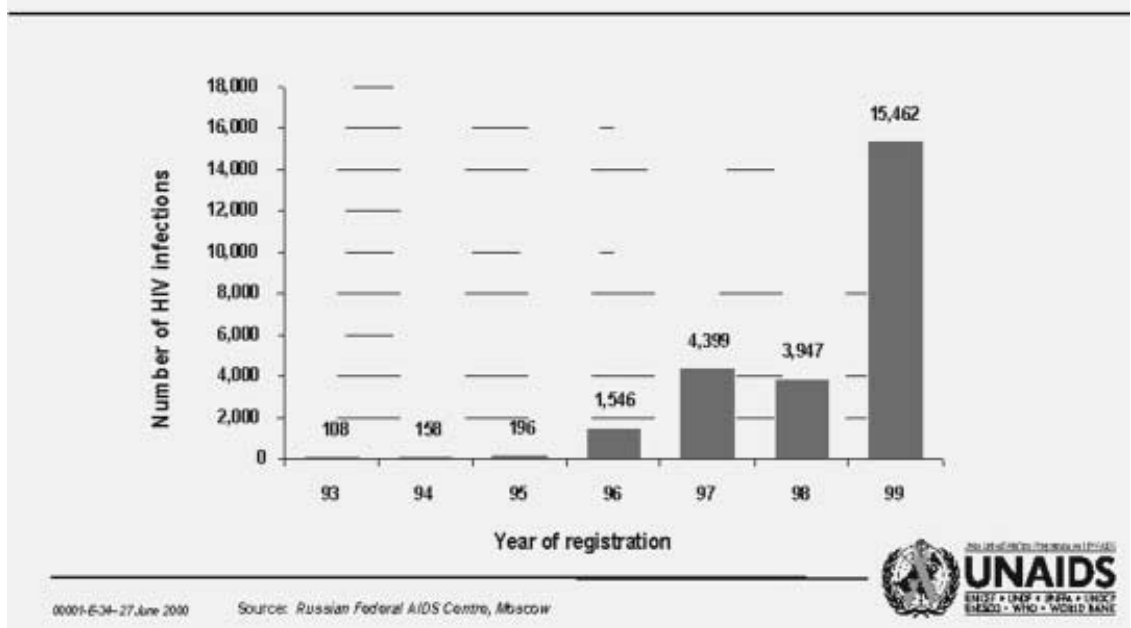

Abb. $4 \Delta$ Anstieg der Zahl der neu diagnostizierten HIV-Infektionen in Russland in den vergangenen Jahren. Der ansteigende Trend setzte sich im Jahre 2000 unverändert fort. Bis Mitte des Jahres waren bereits mehr als $\mathbf{2 0 . 0 0 0 ~ n e u e ~ I n f e k t i o n e n ~ d i a g n o s t i z i e r t ~ w o r d e n ~}$ 
intravenös Drogen konsumiert, sind es in Russland, der Ukraine, Kasachstan und Georgien mehr als 1\%, in bestimmten Städten werden schätzungsweise von 5 bis $7 \%$ der Bevölkerung Drogen injiziert. Bislang ist nur ein kleiner Teil der Drogengebraucher mit HIV infiziert, aber mit der Ausbreitung der Epidemie steigt das Risiko für die bislang verschont gebliebenen von Tag zu Tag.

\section{"In Russland wird ein Anstieg der Gesamtzahl der HIV-Infi- zierten in den kommenden zwei Jahren auf über eine Million erwartet."}

Die Epidemie unter Drogengebrauchern breitet sich in praktisch allen europäischen Nachfolgestaaten der ehemaligen Sowjetunion aus, hat aber noch keine erkennbaren Auswirkungen auf die ostmitteleuropäischen Staaten (Polen, Slowakei, Ungarn etc.) gehabt. Ein plötzlicher, unerwarteter Ausbruch von HIVInfektionen unter finnischen Drogengebrauchern in den Jahren 1998 und 1999 wurde durch den Import einer HIV-Variante ausgelöst, die vermutlich aus Südostasien stammte (Rekombinante aus Subtyp A und Subtyp E) [Liitsola et al., MoPeA2068]. Falls sich jedoch STDund HIV-Epidemie in Osteuropa verei- nen sollten, könnte sich dies auch auf Westeuropa auswirken. Steigende Syphiliszahlen in Finnland, der Slowakei, Teilen Italiens und Deutschlands in den letzten Jahren waren sehr wahrscheinlich auf die Zunahme von STDs in Osteuropa und den steigenden Anteil osteuropäischer Frauen im Sexgewerbe dieser Länder zurückzuführen.

\section{Die sozialen, demografischen und ökonomischen Folgen der Epidemie}

Mit 2,8 Millionen AIDS-bedingten Todesfällen im Jahre 1999 ist die HIV-Infektion mittlerweile der größte Killer unter den Infektionskrankheiten. 95\% der Todesfälle im Jahre 1999 entfielen auf Schwarzafrika und Südostasien, nur $1 \%$ auf die westlichen Industriestaaten. Obwohl die Zahl der HIV-Infizierten in Osteuropa noch kleiner ist als in Westeuropa und die Epidemie viel jünger ist, übersteigt die Zahl der AIDS-Todesfälle in Osteuropa bereits die Westeuropas. Dies ist Ausdruck der schlechteren medizinischen Versorgung und der Nichtverfügbarkeit antiretroviraler Kombinationstherapien in Osteuropa (siehe Abb. 6).

Die größten Lücken reisst AIDS aber zweifellos in Schwarzafrika. Minister, Angestellte, Arbeiter, Bauern, Fischer, Lehrer, Ärzte, Krankenschwestern, Polizisten, Soldaten - alle Gruppen und

\section{Prevalence of syphilis among pregnant women attending antenatal clinics in the Moscow region, 1993 to 1997}

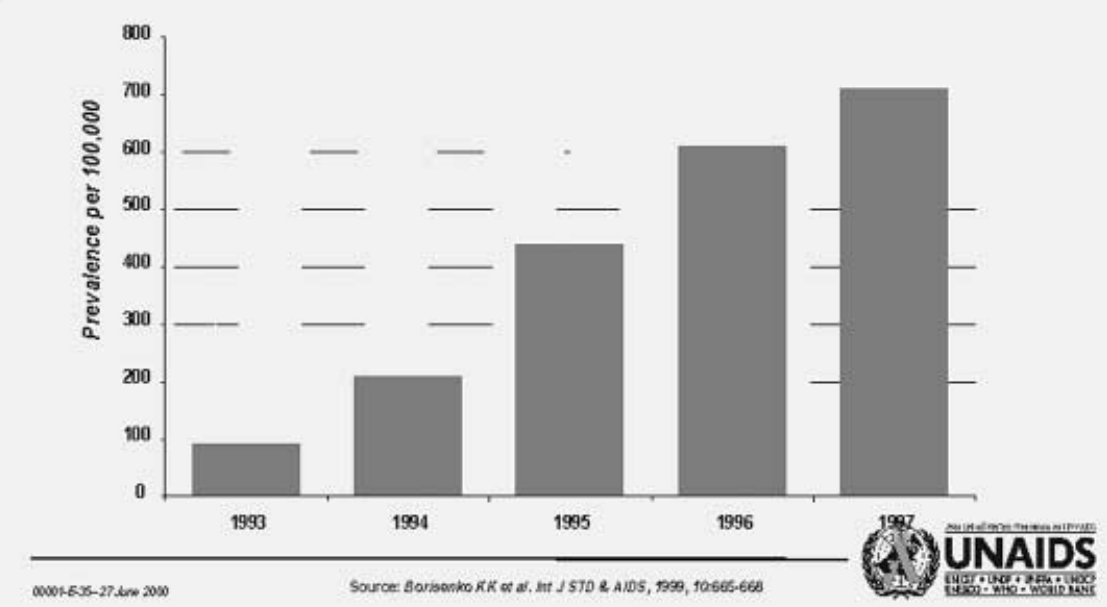

Abb.5. Anstieg der Syphilisprävalenz bei den Schwangerschaftsvorsorgeuntersuchungen in der Region Moskau

Schichten der Bevölkerung sind betroffen. Vor allem im südlichen Afrika führt die Epidemie zu einem Schrumpfen der Bevölkerung in den am stärksten betroffenen Ländern, wobei sich gleichzeitig die Altersstruktur der Bevölkerung auf eine nie da gewesene Art und Weise verändert: die produktiven Altersgruppen, die den Unterhalt für Kinder, Alte und Kranke mit erwirtschaften müssen, schrumpfen dramatisch zusammen (siehe Abb. 7).

Dagegen verblassen die aufgeregten Diskussionen um die Überalterung der Industriegesellschaften, die hierzulande geführt werden. Die mittlere Lebenserwartung in weiten Teilen Süd- und Ostafrikas fällt um 20 bis 30 Jahre und macht damit die mühsam in fünfzig Jahren gewonnenen Fortschritte zunichte (siehe Abb. 8+9). Ein Jugendlicher in Zimbabwe erreicht mit 50\%iger Wahrscheinlichkeit nicht mehr ein Alter von 50 Jahren, seine Altersgenossen in den Nachbarländern haben zum Teil noch geringere Aussichten, ihren 50. Geburtstag noch zu erleben. Die Kindersterblichkeit, die in den meisten Ländern aufgrund der allmählichen Verbesserung der hygienischen Verhältnisse, durch Impfungen und bessere medizinische Versorgung gesunken war, ist seit der Mitte der achtziger Jahre wieder am Steigen (siehe Abb.10). 20 bis 30\% aller Kinder werden in den stärker betroffenen Ländern ohne Mutter und/oder Vater aufwachsen müssen. Für jeden qualifizierteren Arbeitsplatz wird man zwei bis drei Personen ausbilden müssen, um die krankheitsbedingten Ausfälle zu kompensieren. Wenn man angesichts dieser jetzt bereits absehbaren Entwicklungen seiner Phantasie freien Lauf lässt, versteht man, warum die AIDS-Epidemie in Afrika von der USRegierung mittlerweile als Bedrohung der nationalen Sicherheit und vom Sicherheitsrat der Vereinten Nationen als Bedrohung für Sicherheit, Frieden und Entwicklung auf dem afrikanischen Kontinent eingeschätzt wird.

\section{AIDS in Südafrika}

Südafrika ist kein armes Land. Das Prokopfbruttosozialprodukt lag $1994 \mathrm{mit}$ 3040 US \$ pro Kopf höher als das Brasiliens (2970 US \$) oder des EU-Beitrittskandidaten Polen (2410 US \$). Die Verteilung des Reichtums gehört allerdings 


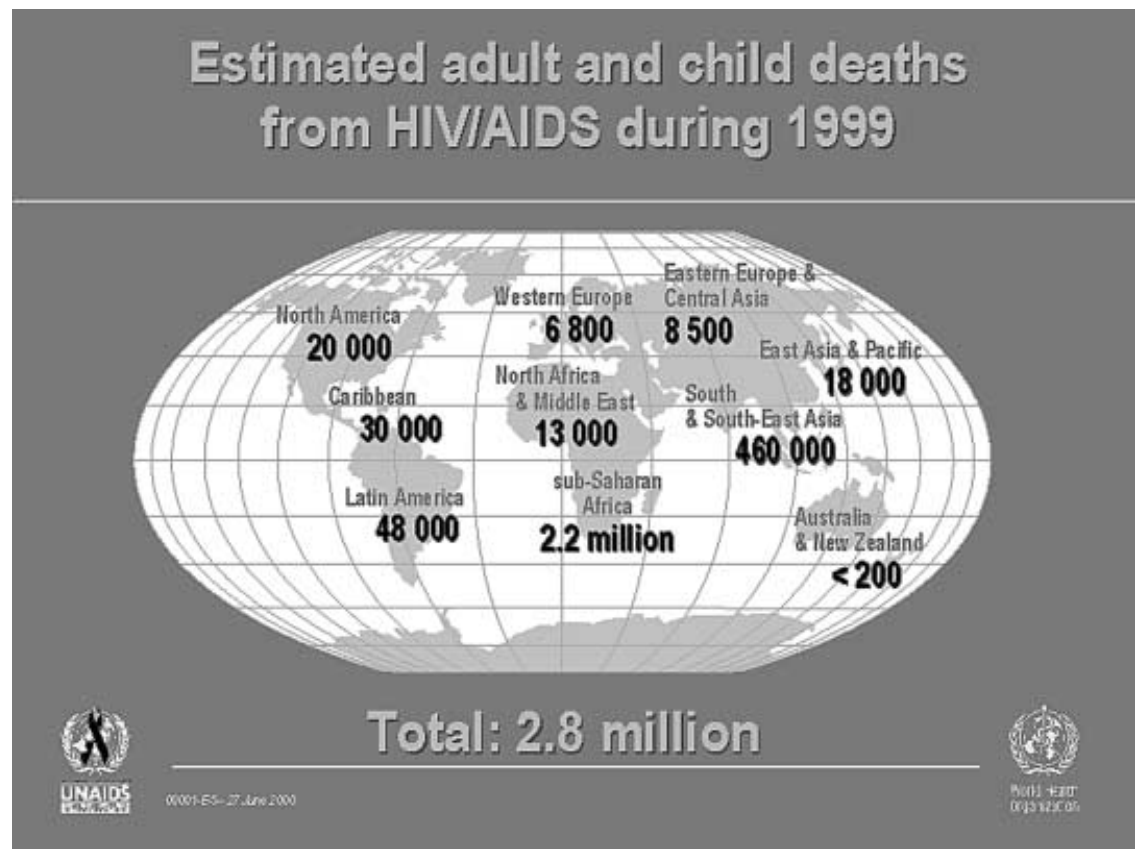

Abb.6 Weltweite Verteilung der 2,8 Millionen AIDS-Todesfälle im Jahre 1999 (Quelle: UNAIDS)

zu den ungerechtesten auf der Welt. Die reichsten $10 \%$ der südafrikanischen Haushalte erhalten $40 \%$ der Einkommen, die ärmsten $40 \%$ erhalten $11 \%$. Der Human Development Index (der sich aus den Faktoren Lebenserwartung, Bildungsniveau und Lebensstandard zusammensetzt) für die weiße Bevölke- rung Südafrikas würde diese unter die zwanzig reichsten Industrienationen einordnen, die schwarze Bevölkerung rangiert dagegen nur knapp oberhalb des untersten Drittels auf dieser Skala, unterhalb Chinas und Ägyptens, knapp über Zimbabwe. Die mittlere Lebenserwartung lag 1990 für die Weißen in Süd-

\section{Projected population structure with and without the AIDS epidemic, Botswana, 2020}

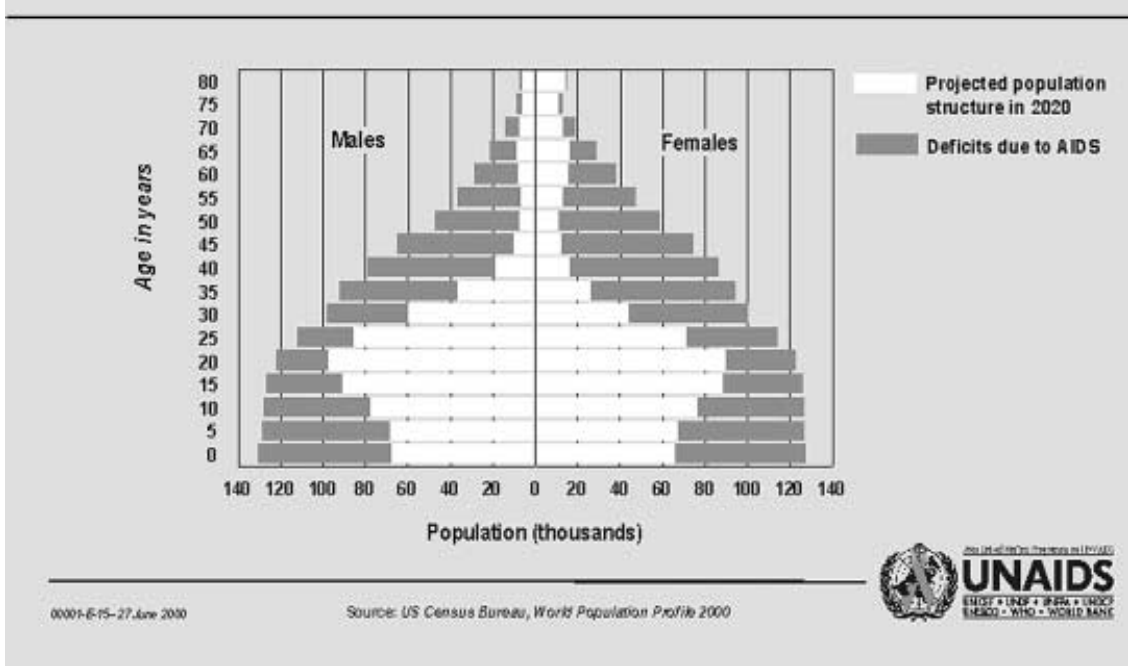

Abb.7 A Alterspyramide von Botswana im Jahre 2020 - die hell markierten Balken geben die auf den aktuellen Infektionsraten projektierte Altersstruktur wieder, die dunklen Balken zeigen, wie sich die Bevölkerung ohne AIDS entwickelt hätte afrika um neun Jahre höher als für die Schwarzen, die Kindersterblichkeit war bei Schwarzen mehr als achtmal höher. 1995 lebten $61 \%$ der schwarzen Haushalte unterhalb der Armutsgrenze, aber nur $1 \%$ der weißen Haushalte. Von den $40 \%$ der ärmsten Haushalte müssen fast $60 \%$ der Einkünfte für Nahrungsmittel ausgegeben werden, von den $10 \%$ der reichsten nur 15\%, wobei die Ausgaben pro Kopf das vierfache der Ausgaben der armen Haushalte betragen. Das Gesundheitswesen ist zweigeteilt: auf den privaten Sektor, der weniger als ein Viertel der südafrikanischen Bevölkerung versorgt, entfallen mehr als 60\% aller Gesundheitsausgaben, die übrige Bevölkerung ist auf das staatliche Gesundheitswesen angewiesen. Nach der Machtübernahme des ANC 1994 wurde zunächst die kostenlose medizinische Behandlung von Schwangeren und Kindern unter sechs Jahren eingeführt, 1996 dann auch eine kostenlose Grundversorgung für alle $\mathrm{Pa}$ tienten. Rein statistisch gesehen ist die Versorgung der Bevölkerung mit Ärzten gut, die große Mehrheit arbeitet aber im Privatsektor. Der 1995 in die Diskussion gebrachte Vorschlag, alle Medizinstudenten nach Abschluss ihres Studiums zwei Jahre im öffentlichen Gesundheitsdienst arbeiten zu lassen, stieß auf so erbitterten Widerstand, dass der Zeitraum auf ein Jahr reduziert werden musste. Ausländische Ärzte aus Kuba, England und Deutschland lindern die Versorgungslücken (May J (Editor) 2000): Poverty and Inequality in South Africa: Meeting the Challenge. Zed Books, London \& New York).

\section{"Die Prävention wurde den Selbsthilfegruppen überlas- sen, der Staat blieb untätig."}

Vor diesem Hintergrund ist die Entwicklung der HIV/AIDS-Epidemie in Südafrika zu sehen. Die ersten AIDS-Fälle in Südafrika betrafen Mitte der achtziger Jahre weiße homosexuelle Männer. Ein Surveillancesystem wurde etabliert, und ein Blutspenderscreening auf HIV wurde eingeführt, ansonsten blieb die Prävention weitgehend den Selbsthilfegruppen überlassen. Der Staat blieb untätig. Als Anfang der neunziger Jahre erkennbar wurde, dass sich unter der schwarzen Bevölkerung eine Epidemie entwickelte, wurden einige Informations- und 


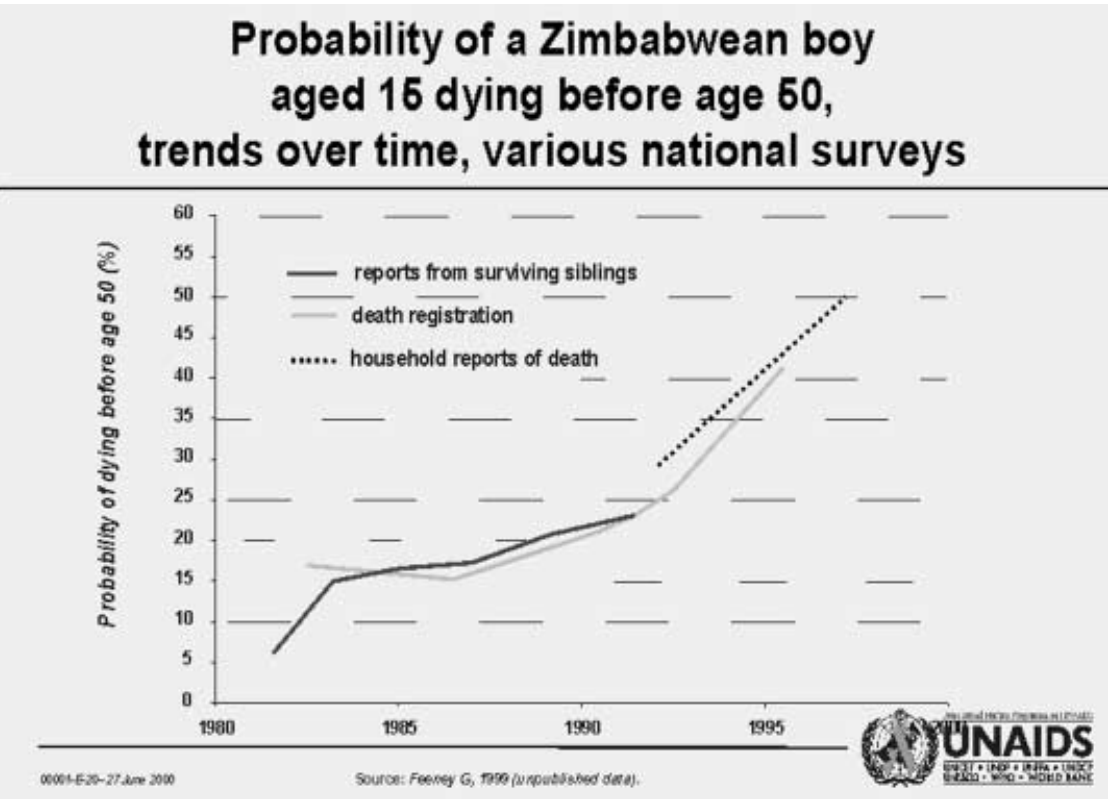

Abb. 8 Entwicklung der Aussichten für einen 15-jährigen Jungen in Zimbabwe, sein 50. Lebensjahr zu erreichen, im Verlauf der letzten 20 Jahre. Angaben aus verschiedenen Datenquellen

Ausbildungszentren gegründet, in denen Berater geschult wurden. Diese waren alle in größeren Städten angesiedelt, kein einziges in einer ländlichen Region. Die eigentliche Antwort auf die Epidemie kam jedoch aus dem Bereich der Selbsthilfegruppen, die sich im Nationalen AIDS-Koordinierungskomittee für Südafrika (NACOSA) zusammenschlossen und eine nationale AIDS-Strategie entwickelten. Vor der ANC-Machtübernahme wurden diese Organisationen hauptsächlich aus dem Ausland finanziell unterstützt. Diese finanzielle Unterstützung fiel für einen Teil der Organisationen nach der Machtübergabe an die schwarze Bevölkerungsmehrheit weg. Der von NACOSA entwickelte nationale AIDS-Plan bildete die Basis des AIDSProgramms der neuen Regierung. Die Umsetzung erfolgte jedoch nur stockend und mit einigen Fehltritten. Die notwendige Restrukturierung der staatlichen Verwaltung verminderte zeitweise nicht unerheblich deren Effizienz. Massenmediale Kampagnen über das Fernsehen hatten relativ wenig Effekt, unter anderem, weil sie zu wenig auf die Zielpopulationen zugeschnitten waren und die lokalen Gegebenheiten und verschiedenen Kulturen nicht ausreichend berücksichtigten. Das Radio, welches sich als Aufklärungsmedium in einer derartigen Situation besonders angeboten hätte, wurde nicht genutzt. Für die AIDS-AufOstafrikas in den vergangenen 50 Jahren der zweiten Hälfte der neunziger Jahre eingeführt. Wenig Aufmerksamkeit wurde bislang der medizinischen und psychosozialen Betreuung von HIV-Positiven und AIDS-Kranken gewidmet. Gegenüber den städtischen Regionen sind die ländlichen sehr viel schlechter versorgt. Die gesamten staatlichen Ausgaben für das nationale AIDS-Programm zwischen 1992 und 1997 betrugen 180 Mio. Rand (nach derzeitigen Wechselkurs knapp 60 Mio. DM, d. h. durchschnittlich 10 Mio. DM/Jahr).

Die besten landesweiten Surveillancedaten liefern die Untersuchungen aus den Vorsorgeprogrammen für Schwangere. In den staatlichen Kliniken stieg die HIV-Prävalenz bei Schwangeren von 0,7\% im Jahre 1990 auf 22,5\% im Jahre 1999, in der Provinz Kwazulu-Natal, deren größte Stadt Durban ist, liegt die HIV-Prävalenz bei Schwangeren mit 32,5\% im Jahre 1999 am höchsten (Abb. 11).

Zahlen aus dem nichtstaatlichen Krankenversorgungsbereich liegen nur spärlich vor, so dass die Prävalenzzahlen Repräsentativität in erster Linie für die ärmere Bevölkerungsmehrheit beanspruchen können. Einzelne Untersuchungen, z. B. bei Beschäftigten einer landesweit operierenden Firma, zeigen deutliche HIV-Prävalenzunterschiede zwischen schwarzen und weißen Beschäftigten, wobei aber auch bei weißen

\section{Changes in life expectancy in selected African countries with high HIV prevalence, 1950 to 2000}

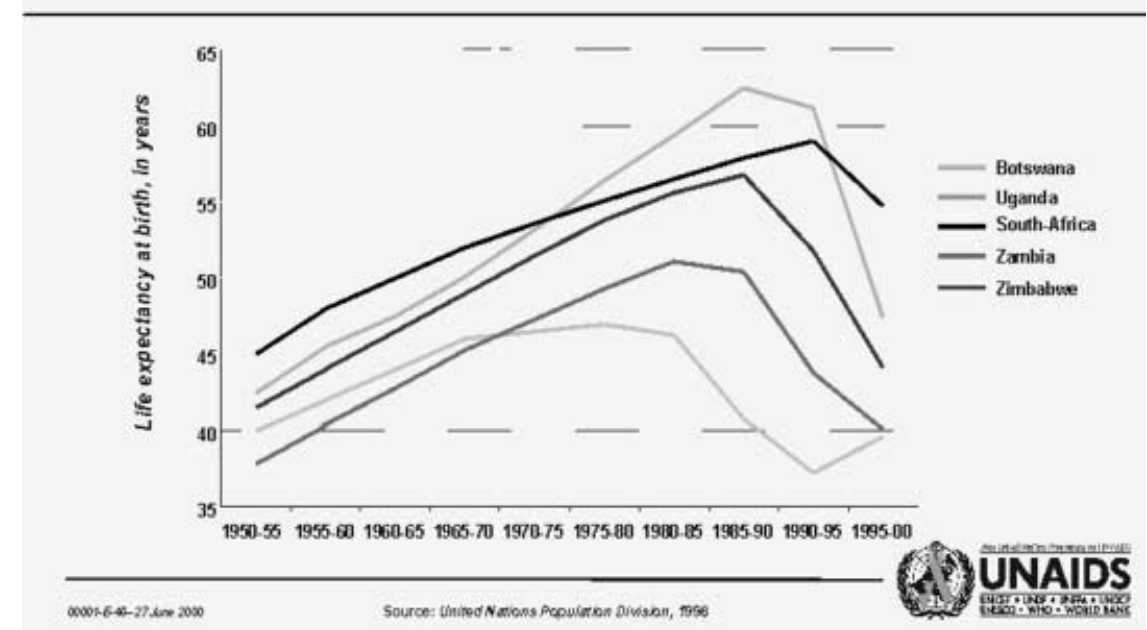

Abb. $9 \Delta$ Entwicklung der mittleren Lebenserwartung in einigen ausgewählten Ländern Süd- und 


\section{Trends in mortality among children under five years old and end-1999 adult HIV prevalence rate, selected African countries, 1981-1996}

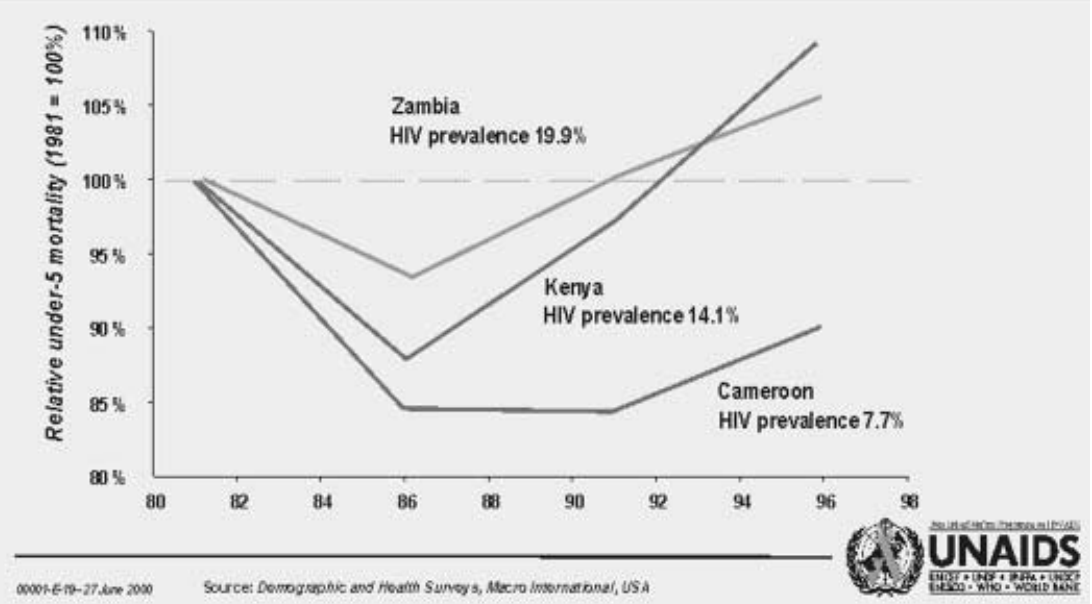

Abb. $10 \Delta$ Entwicklung der Kindersterblichkeit in drei ausgewählten Ländern Schwarzafrikas und Zusammenhang mit der HIV-Prävalenz bei Erwachsenen

Beschäftigten mit einer Prävalenzrate von $2,1 \%$ (vs. $13,9 \%$ bei den schwarzen Beschäftigten) deutlich höhere Infektionsraten beobachtet werden als in vergleichbaren Populationen in allen entwickelten Industriestaaten [Calvin et al., MoPeC2358]. Ein positiver HIV-Status korrelierte mit der Art der Tätigkeit (angelernt 14,7\%, Management 3,3\%), der Art der Unterkunft, dem Ausmaß an Mobilität und dem Sexualverhalten. $\mathrm{Zu}$ den wichtigsten Faktoren, die für die rasche Ausbreitung von HIV verantwortlich sind, zählen eine sehr hohe Prävalenz sexuell übertragbarer Infektionen (11 Mio. Behandlungsepisoden/Jahr), hohe Partnerzahlen und niedrige Kondomverwendungsraten. Diesen $\mathrm{zu}$ Grunde liegen sozioökonomische Faktoren wie Armut, Wanderarbeit bzw. räumliche Trennung der Arbeiter und Arbeitssuchenden von ihren Familien, Prostitution bzw. vielfältige Formen des Austausches materieller Güter gegen sexuelle Dienstleistungen, der niedrige soziale Status der Frau, weitverbreitete Gewalt gegen Frauen (Südafrika hat eine sehr hohe Rate von Vergewaltigungen, die nur zu einem kleinen Prozentsatz in den Kriminalstatistiken auftauchen), Analphabetentum und schlechter Bildungsstatus. Die meisten dieser Faktoren sind typisch für Entwicklungsländer in einem bestimmten Entwicklungsstadium, sind aber in Südafrika als Erbe der jahrzehntelangen Apartheidpolitik besonders stark ausgeprägt. Dies gilt z. B. für die interne Bevölkerungsmigration. Eine Studie, die verschiedene Formen der Arbeitsmigration und deren Auswirkungen auf das HIV-Infektionsrisiko untersuchte, fand deutlich höhere Infektionsraten bei Arbeitern, die lange von zu Hause weg waren. Bei den Partnern, (Quelle: Department of Health, South Africa/UNAIDS) meist die auf dem Land lebende Ehefrau, waren die Infektionsraten dagegen bei denjenigen am höchsten, bei denen die Männer häufiger und regelmäßiger (ca. monatlich) nach Hause kamen (siehe Tabelle 1) [Lurie et al., MoPpD1049].

Trotz gesetzlichen Diskriminierungsverbotes sind HIV-Infizierte und AIDS-Kranke hoch stigmatisiert. Schlagzeilen machte z. B. die Ermordung von Gugu Dlamini kurz vor Weihnachten 1998. Dlamini hatte sich wenige Wochen vorher am Welt-AIDS-Tag in einer Radiosendung und im Fernsehen als HIV-infiziert zu erkennen gegeben. Von ihren Nachbarn wurde sie daraufhin beschuldigt, Schande über ihre Gemeinde zu bringen. In der Nacht auf den 22 . Dezember wurde sie in ihrem Haus von einem aufgebrachten Mob attackiert, mit Steinen beworfen und mit Fäusten und Stöcken zu Tode geprügelt. Wenn man sich mit einfachen Menschen unterhält, offenbaren sich nicht selten fatale Unsicherheiten und Fehlinformationen hinsichtlich des Wissens über HIV und AIDS, die offensichtlich durch die massenmediale Kommunikation über das Thema bislang nicht beseitigt werden konnten. Auch bei Menschen, die prinzipiell über alle wesentlichen Informationen verfügen, herrscht die meist irrige Überzeugung, man selbst sei durch AIDS nicht gefährdet. Begünstigt wer-

\section{HIV prevalence among ANC attendees in South Africa, 1990 to 1999}

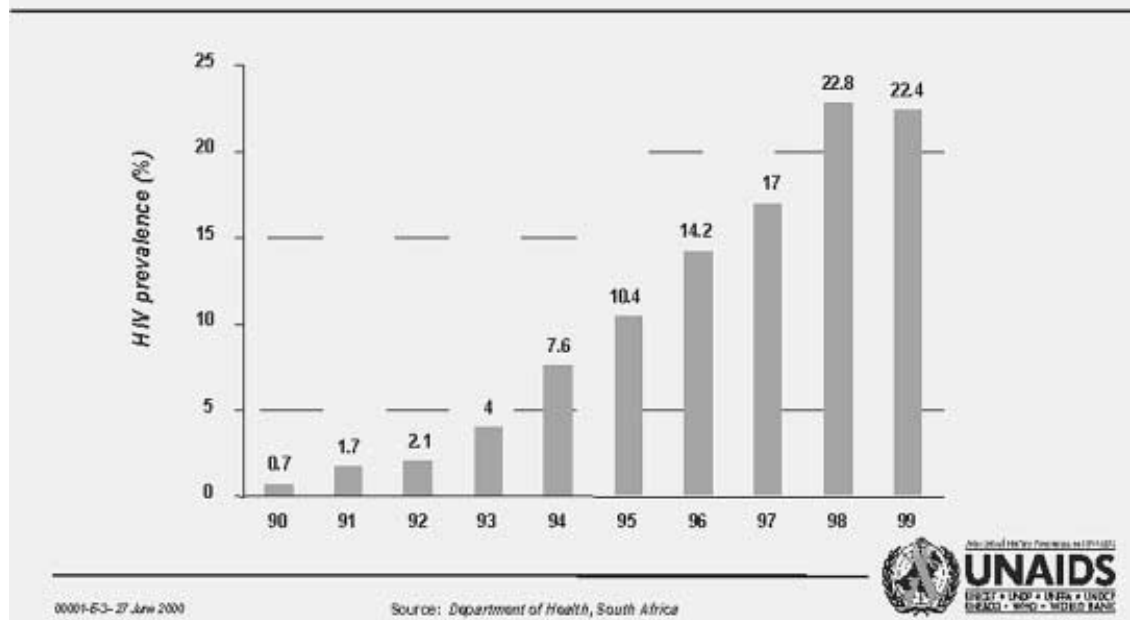

Abb. $11 \Delta$ HIV-Prävalenzen in der Schwangerenvorsorge in Südafrika im Verlauf der neunziger Jahre 
Tabelle 1

Zusammenhang zwischen Typ der Arbeitsmigration und HIV-Status (MoPpD1049)

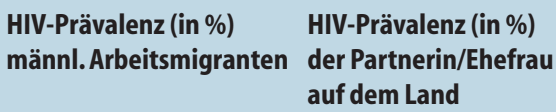

HIV-Prävalenz (in \%) HIV-Prävalenz (in \%)

männl. Arbeitsmigranten der Partnerin/Ehefrau auf dem Land

\section{Arbeitsmigranten mit zwei-}

bis viermal Heimaturlaub/Jahr

Arbeitsmigranten mit

monatl. Heimaturlaub

Keine Arbeitsmigration
27,7

15,2

22,4

20

17,8

12,9 den derartige Illusionen durch die trotz erschreckender Zahlen (geschätzte 120.000 AIDS-Tote im Jahre 1998) noch relativ geringe Sichtbarkeit von AIDS.

Die häufigsten klinischen Manifestation sind die auch unabhängig von den HIV-assoziierten Fällen weitverbreitete Tuberkulose und andere Atemwegsinfektionen. Schwere chronische Durchfallerkrankungen, die zur Krankenhausaufnahme führen, stehen dagegen fast alle in Zusammenhang mit einer HIV-Infektion. Eine Klinik aus einer ländlichen Region Kwazulu-Natals berichtet, dass 1998 bereits mehr als die Hälfte aller Patienten HIV-positiv war. Gegenüber 1991 hatte sich die Zahl der Aufnahmen verdreifacht, das Durchschnittsalter der Patienten fiel dabei von durchschnittlich 45,4 auf 36,9 Jahre, die Mortalität stieg von 7,5 auf $13,1 \%$ [Reid et al., ThPeB5206;
ThPeB5207]. Dabei ist aufgrund der Geschwindigkeit der Epidemie und der langen Inkubationszeiten von AIDS der überwiegende Teil der in den vergangenen zehn Jahren infizierten Personen noch symptomlos, und die Betroffenen wissen nichts von ihrer Infektion.

\section{Verleugnung persönlicher Betroffenheit und Gefährdung durch AIDS}

Ein hervorstechendes Merkmal des gesellschaftlichen und individuellen Umgangs mit dem Risiko AIDS in den meisten Ländern Afrikas ist ein hohes Maß an Problemverleugnung, häufig sogar bei gleichzeitig gutem Wissensstand $\mathrm{zu}$ Übertragungswegen und -risiken. Personen, deren HIV-Infektion bekannt ist oder bei denen eine solche vermutet

\section{Knowledge and beliefs concerning AIDS among AIDS orphans, Rusinga Island, Kenya}

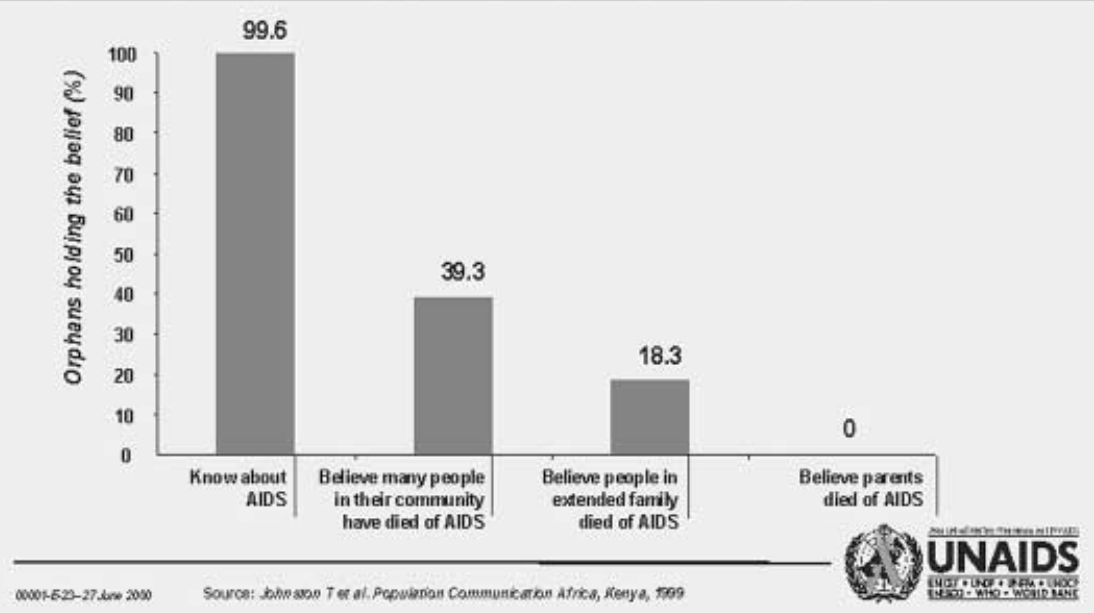

Abb. $12 \Delta$ Wissen über AIDS und Bezug zur eigenen Situation bei einer Gruppe von AIDS-Waisen in Kenia

wird, laufen Gefahr, von medizinischem Personal nicht behandelt zu werden, Arbeit und Wohnung zu verlieren, von ihrem Partner verlassen oder ihrer Familie verstoßen zu werden, im schlimmsten Fall, wie oben geschildert, sogar ermordet $z u$ werden. Genauso wie in den Industrieländern am Beginn der HIV-Epidemie Diskussionen um Ausgrenzungsund Diskriminierungsmaßnahmen (z. B. Isolierung und Tätowierung von HIVInfizierten, Zwangsuntersuchungen etc.) geführt wurden, wurden und werden solche Diskussionen auch in Afrika, Asien und Lateinamerika geführt. Aber während bei uns solche Vorschläge höchstens in Randbereichen realisiert wurden und im Großen und Ganzen auf Ablehnung stießen, wurden in einigen Ländern Afrikas Gesetze verabschiedet, die HIV-Infizierte klar diskriminieren und damit zusätzlich die Bereitschaft hemmen, sich mit der Möglichkeit infiziert zu sein auseinander zu setzen.

Solange es keine Unterstützungssysteme oder therapeutischen Konsequenzen gibt, fügt die Kenntnis, HIV-infiziert zu sein, nur den täglichen Problemen ein riesiges weiteres, noch dazu unlösbares, hinzu. Je größer die Alltagsprobleme bereits sind, desto geringer wird die Bereitschaft sein, sich mit einem solchen zusätzlichen Problem zu konfrontieren. Die Abwehrhaltung ist so groß, dass sie sogar über den Tod hinaus Bestand hat und auf die Kinder "vererbt" wird. Illustriert wird dies durch eine Untersuchung bei Kindern in Kenia, die ihre Eltern durch AIDS verloren haben. Obwohl fast alle die wesentlichen Grundkenntnisse über AIDS besaßen und $40 \%$ immerhin angaben, dass viele Menschen in ihrer Umgebung an AIDS verstorben seien, wollten nur $18 \%$ wahrhaben, dass es in ihrer engeren Verwandtschaft AIDS-Tote gegeben habe. Keines der Kinder konnte zugeben, dass seine Eltern an AIDS verstorben waren. Als häufigste Todesursache wurde ein Fluch oder Hexerei angegeben (Abb.12).

In Carltonville, einer Goldbergwerkssiedlung in Südafrika, wurde eine Untersuchung durchgeführt, an der sich über 2200 Einwohner beteiligten. Die HIV-Prävalenzraten erreichten $29 \%$ bei den Bergleuten, knapp 70\% bei Prostituierten bzw. Frauen, die Sex gegen materielle Zuwendungen tauschen. Auch andere sexuell übertragbare Infektionen sind weit verbreitet. Etwa 10\% der Untersu- 
chungsteilnehmer, Männer wie Frauen, waren mit Syphilis infiziert. Kondome wurden nur selten und unregelmäßig benutzt. Nur 23\% der Befragten gaben an, mit ihrem letzten Gelegenheitspartner ein Kondom verwendet $\mathrm{zu}$ haben. Mehr als 85\% konnten jedoch Fragen nach HIV-Übertragungswegen und -risiken korrekt beantworten. Über 40\% der Befragten sahen sich selbst durch AIDS nicht als gefährdet an, davon waren jedoch 22\% bereits infiziert (Abb.13).

Der HIV-Test wurde mit Zustimmung der Untersuchten, aber ohne vorherige Testberatung, durchgeführt. Die Teilnehmer konnten wählen, ob sie das Testergebnis erfahren wollten oder nicht. Allen Teilnehmern wurde zugesichert, dass zusammen mit der Ergebnismitteilung eine ausführliche Beratung erfolgen würde. Kein Teilnehmer fragte nach seinem Testergebnis [Williams et al., MoPpC1026]. Im Rahmen einer Kohortenstudie, die ebenfalls in Carltonville durchgeführt wird, und für die bis zum Berichtszeitpunkt knapp 350 Teilnehmer rekrutiert wurden, wird ebenfalls ein HIV-Test angeboten. In dieser Studie werden die Teilnehmer ausdrücklich zum Test ermutigt, und vor und nach dem Test erfolgt eine Beratung. Zwei Drittel der Teilnehmer waren an ihrem Testergebnis interessiert, ein Drittel nicht. Die HIV-Prävalenz bei den mit- geteilten Testergebnissen betrug $18,7 \%$, bei den Teilnehmern, die ihr Ergebnis nicht wissen wollten, lag sie bei $25,7 \%$ [Mkaya-Mwamburi et al., MoPeC2376]. Dies zeigt die große Bedeutung, die eine persönliche und qualifizierte Beratung bei HIV-Testangeboten hat.

Im Rahmen einer Mikrobizidwirksamkeitsstudie wurden 120 Prostituierte, die an Lastwagenrastplätzen in Kwazulu-Natal arbeiten, monatlich auf HIV untersucht und in regelmäßigen Abständen persönlich interviewt. Die Frauen konnten auch in dieser Studie entscheiden, ob sie das Testergebnis wissen wollten. Unabhängig davon, ob Frauen ein positives oder negatives Testergebnis mitgeteilt erhielten, fuhren sie fort, an den Rastplätzen zu arbeiten und Sex ohne Kondom zu praktizieren, weil die Kunden für Sex mit Kondom nur die Hälfte zu zahlen bereit waren. Auch die Mehrheit der festen Partner war nicht bereit, innerhalb der Partnerschaft Kondome zu benutzen. Frauen, die im Verlauf der Studie serokonvertierten, waren ebenfalls nicht daran interessiert, ihren HIV-Status zu erfahren. Sie begründeten ihr Desinteresse damit, dass die Kenntnis ihres Serostatus sie nur psychisch belaste, ihre Partnerschaft gefährde und bei Bekanntwerden ihre Einkommensquelle ruiniere [Morar et al., MoPpC1030]. Diese Erfahrung weist auf

\section{HIV prevalence rate and frequency of sexually transmitted infection (STI) episodes, Carletonville miners, South Africa, 1991-1998}

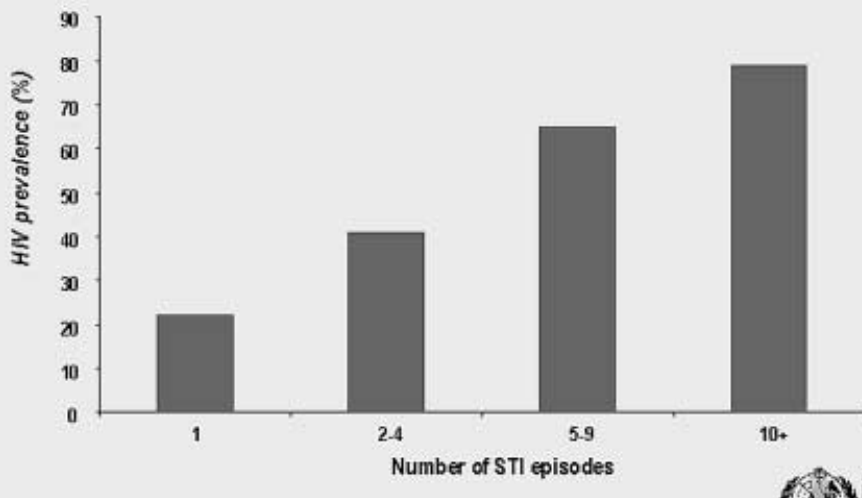

$0001-602-27.600 \times 2000$

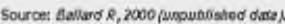

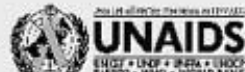

Abb. $13 \Delta$ Zusammenhang zwischen HIV-Prävalenz und Anzahl durchgemachter sexuell übertragbarer Infektionen (STI) in der Bergwerkssiedlung Carletonville in Südafrika (Quelle: UNAIDS) die entscheidende Rolle des sozialen Umfeldes für die Effektivität von Testund Beratungsangeboten hin: wenn der Boden für die intendierten Verhaltensänderungen nicht bereit ist, kann das Wissen um den eigenen positiven Serostatus nicht konstruktiv umgesetzt werden, sondern führt nur zu einer zusätzlichen psychischen Belastung.

In einer Studie zur Beratung von Tuberkulose-Patienten in Zambia wurde im Beratungsgespräch auch der $\mathrm{Zu}$ sammenhang zwischen HIV und Tuberkulose angesprochen und den Patienten ein HIV-Test angeboten [Ayles et al., TuPeD3780]. Folgende Fallbeschreibungen sind typisch für die auftauchenden Probleme:

D Ein 17-jähriger TB-Patient lehnt nach Beratung einen HIV-Test ab, weil seine Eltern noch nicht wissen, dass er bereits mit Mädchen geschlafen habe. Im Falle eines positiven Testergebnisses sieht er keine Möglichkeit, mit seinen Eltern darüber zu reden.

D Eine 29-jährige verheiratete Patientin lehnte einen HIV-Test für sich alleine ab. Nach Rücksprache mit ihrem Mann erschienen beide zum Test. Ihr Testergebnis war positiv, sein Ergebnis negativ. Sieben Monate später verließ ihr Mann sie mit einer anderen Frau und ließ sie mit drei Kindern zurück.

D Bei einer 41-jährigen verheirateten Mutter von fünf Kindern wurde eine Tuberkulose diagnostiziert. Nach Beratung stimmte sie einem HIV-Test zu, der positiv ausfiel. Sie war aber nicht bereit, das Ergebnis ihrem Ehemann mitzuteilen.

D Eine 48-jährige alleinstehende Mutter erkrankte an einem TuberkuloseRezidiv. Das Beratungsgespräch verlief so lange in angenehmer, konstruktiver Atmosphäre, als die Tuberkulose Thema war. Sobald die Rede auf HIV kam, klagte sie, sie sei zu erschöpft, um das Gespräch fortzusetzen. Sie erklärte, sie könne nicht mit HIV infiziert sein, denn sie habe keine Zeit, sich mit Männern abzugeben, und HIV sei eine Erkrankung, die nur Prostituierte betreffe.

In den Fallgeschichten zeigt sich, dass die Betroffenen durchaus in der Lage sind, mit einer bekannten (und behandelbaren) Krankheit umzugehen. Die Doppelbelastung durch zwei Diagnosen, 


\section{Percentage of 15-19 girls who do not know that a HIV-infected person may look healthy, 1994-1999}

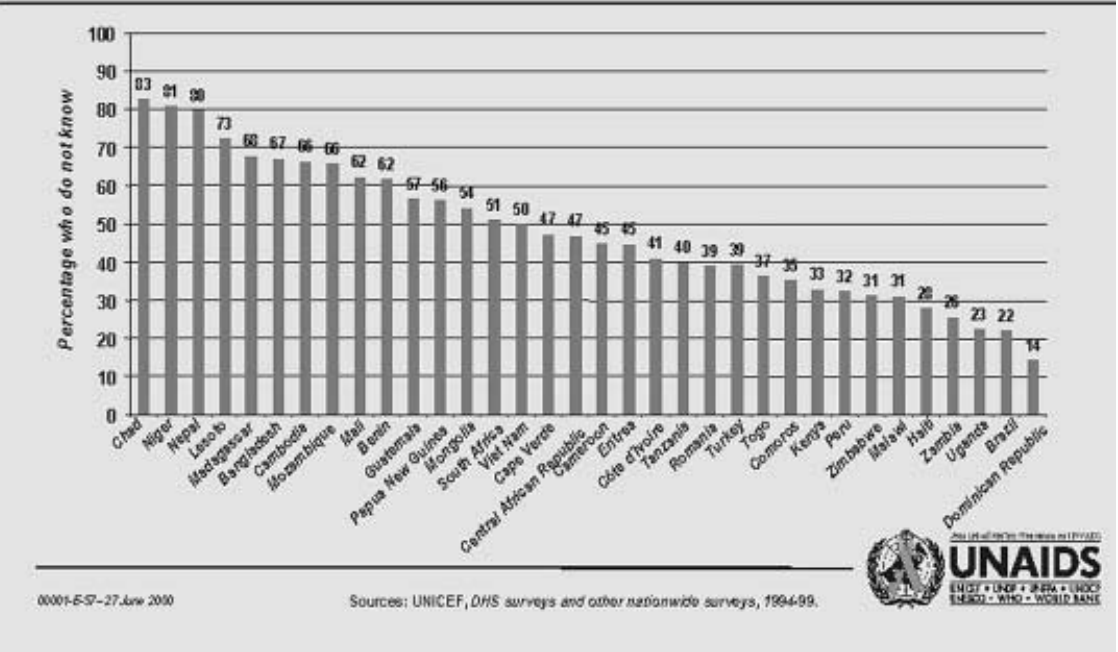

Abb. $14 \Delta$ Anteil weiblicher Teenager in verschiedenen Ländern, die nicht wissen, dass ein HIV-Infizierter gesund aussehen kann

eine davon hoch stigmatisiert, die mangelnde Behandelbarkeit und vor allem die bei Frauen - nicht zu Unrecht - stark ausgeprägte Angst vor Scheidung oder Verlust des Partners stellen aber wesentliche Hinderungsgründe dafür dar, sich mit der Möglichkeit einer HIV-Infektion auseinander zu setzen. Die besondere Belastung von Frauen, insbesondere Frauen in festen Partnerschaften, ist eine Beobachtung, die sich in fast allen Studien zu HIV-Test- und Beratungsangeboten wiederholt. Findet ein HIV-Test nur bei der Frau statt, hat diese oft Angst, ein positives Ergebnis dem Partner mitzuteilen. Vorzuziehen ist, wo immer möglich, die Paarberatung, der gemeinsame Test und die gemeinsame Ergebnismitteilung mit entsprechender Beratung. Insbesondere im Zusammenhang mit HIV-Tests bei Schwangeren wird aber die Erfahrung gemacht, dass der männliche Partner nur selten bereit ist, sich ebenfalls testen zu lassen. Bei diskordantem Ergebnis der HIV-Testung ist die Frau in der Regel die leidtragende, egal ob sie selbst oder ob ihr Partner positiv ist. Frauen haben oft keine Möglichkeit, von ihrem Partner die Verwendung von Kondomen zu verlangen oder im Falle seiner Weigerung, Kondome zu verwenden, die Beziehung zu beenden. Ist umgekehrt der Mann negativ und die Frau positiv, muss diese nicht selten damit rechnen, geschlagen oder verlassen zu werden. Wenn Kinder da sind, wird sie im Zweifelsfall mit ihnen sitzen gelassen.

Test- und Beratungsangebote müssen daher in die Lage versetzt werden, vor allem Frauen die soziale, physische, psychische und finanzielle Unterstützung zu gewähren oder zu vermitteln, die sie in der jeweils konkreten Situationen benötigen, wenn bei ihnen eine HIV-Infektion diagnostiziert wird. Dies ist bei vielen Test- und Beratungsangeboten in Afrika bislang nicht der Fall, weshalb es nicht verwundern kann, dass viele dieser Angebote kaum genutzt werden bzw. die Nutzung solcher Angebote nur sehr beschränkt präventive Effekte zeigt. Test- und Beratungsangebote beschränken sich in der Regel auf die reine Testdurchführung, für die Folgeprobleme fühlen sie sich nicht mehr zuständig bzw. können sie keine Hilfen anbieten. Ein zusätzliches Problem kann die mangelnde Kompetenz und fehlendes Einfühlungsvermögen der Berater darstellen [Van Rooyen TuPeD3788].

Wenn, beispielsweise in ausreichend finanzierten Studien, eine kompetente Beratung erfolgt und auch auf die Bedürfnisse der Getesteten und Ratsuchenden eingegangen wird, können solche Angebote klar messbare positive präventive Effekte haben, wie eine Reduzierung der Zahl ungeschützter Kontakte, sowohl mit nichtprimären als auch mit primären Partnern [3]. Eine weitverbreitete Fehlinformation in Afrika bleibt die mangelnde Kenntnis darüber, dass HIV-Infizierte über lange Zeit beschwerdefrei leben, aber trotzdem infektiös sein können. Die HIV-Infektion ist für viele verknüpft mit dem Bild des abgemagerten AIDS-Kranken, was nicht verwundern kann angesichts der Tatsache, dass kaum jemand gesund aussehende HIV-positive Personen kennt (Abb. 14).

\section{Mutter-Kind-Übertragung}

Seit 1994 ist bekannt, dass durch eine antiretrovirale Therapie bei Schwangeren und Neugeborenen das HIV-Übertragungsrisiko von der Mutter auf das Kind reduziert werden kann. Ohne Behandlung liegt die Übertragungswahrscheinlichkeit - in Abhängigkeit von der mütterlichen Viruslast - bei nichtstillenden Frauen in einer Größenordnung von 15 bis $25 \%$, bei stillenden Frauen erhöht sich die Übertragungsrate auf ca. 35 bis 40\%. Etwa 3,6 Mio. Kinder sind im Verlauf der AIDS-Epidemie bislang an AIDS verstorben, derzeit leben etwa 1,2 Mio. Kinder weltweit mit einer HIV-Infektion, neun von zehn davon in Schwarzafrika. Allein im Jahre 1999 wurden mehr als 600.000 Kinder geboren, die sich über ihre Mutter infiziert haben (Abb. 15).

In den Industriestaaten ist in den vergangenen Jahren durch die medikamentöse Prophylaxe der Mutter-KindÜbertragung, z. T. kombiniert mit frühzeitiger Schnittentbindung, sowie durch Verzicht auf Stillen und Ersatz durch künstliche Babynahrung die MutterKind-Übertragungsrate auf unter $5 \%$ gesunken. Die meisten Mutter-Kind-Übertragungen sind inzwischen darauf zurückzuführen, dass Schwangere entweder gar keine medizinische Betreuung in der Schwangerschaft erfahren oder die HIVInfektion nicht erkannt wird oder zum Zeitpunkt der Geburt eine Resistenz gegen die eingesetzten Medikamente vorliegt. Die folgenden Ausführungen beziehen sich daher auf die Situation in Entwicklungsländern und nicht auf die Behandlungspraxis in den Industriestaaten.

Aus Unkenntnis des Übertragungszeitpunktes wurde in der ersten Interventionsstudie mit der antiretroviralen Behandlung (Zidovudin-Monotherapie) bereits ab der 14. Schwangerschaftswoche begonnen. Unter der Geburt wurde Zidovudin als intravenöse Infusion ge- 


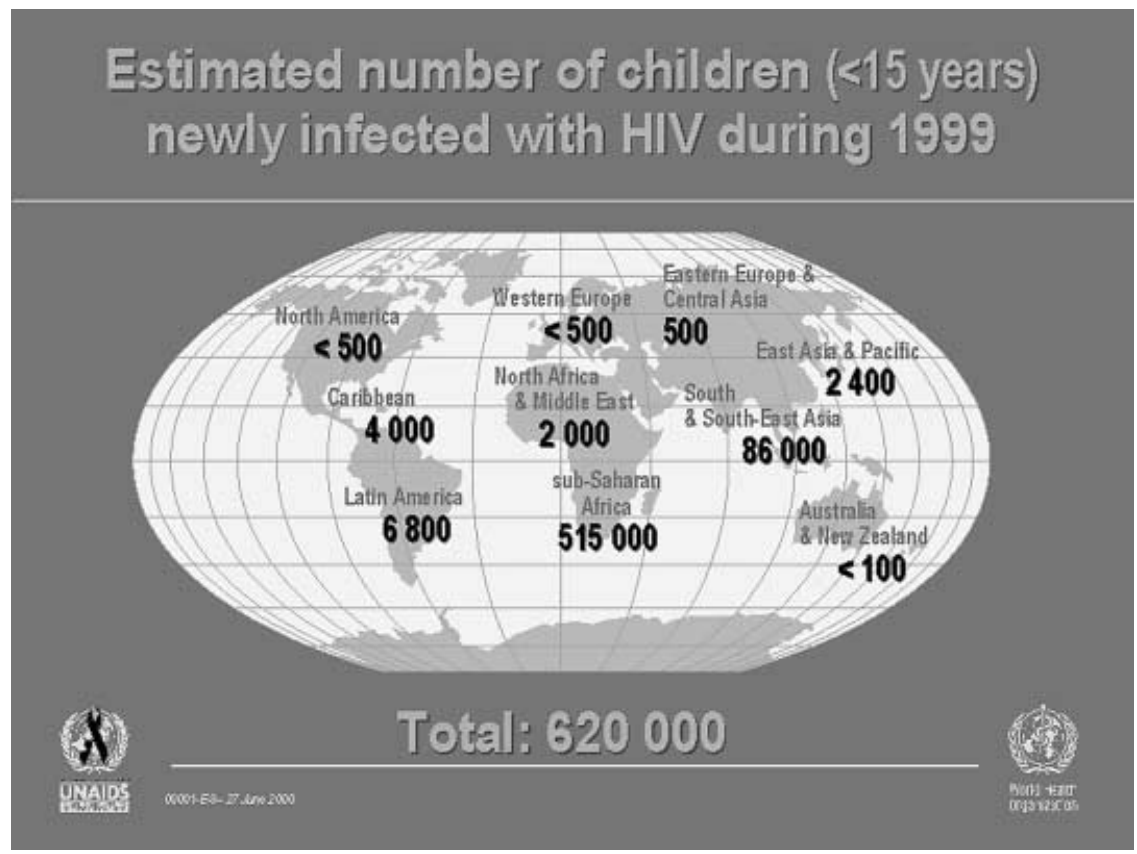

Abb. $15 \Delta$ Geschätzte Zahl und Verteilung der im Jahr 1999 über ihre Mutter mit HIV infizierten Kinder (Quelle: UNAIDS)

geben, und das Neugeborene erhielt das Medikament als Sirup viermal täglich über die ersten sechs Lebenswochen. Dieses Prophylaxeregime kostet etwa 800 bis 1000 US \$ und reduziert die Übertragungsrate bei Verzicht auf Stillen auf ca. ein Drittel (ca. 8 bis 9\%). Da diese Form der Prophylaxe zu komplex und zu teuer für die meisten Entwicklungsländer war, wurde eine Reihe von Studien mit kürzeren und einfacheren Prophylaxeregimen durchgeführt. Ergebnis dieser Studien war, dass auch mit kürzeren Regimen und Ersatz der ZDVInfusion durch orale Medikation während der Geburt eine deutliche Reduktion der Übertragungsrate zu deutlich niedrigeren Kosten (200 bis 400 US \$) erreichbar ist. Die Studien zeigen, dass alle Komponenten der Prophylaxe (Medikamentengabe in den letzten Schwangerschaftswochen, unter der Geburt und Prophylaxe beim Neugeborenen in den ersten Tagen/Wochen) zur Wirksamkeit beitragen.

Die Dauer der Prophylaxe kann mit akzeptablen, geringen Wirksamkeitsverlusten verkürzt werden auf einen Beginn in der 28. bis 36 . Schwangerschaftswoche, die Gabe beim Neugeborenen sollte mindestens über die erste Lebenswoche erfolgen. Eine thailändische Studie zeigt, dass - bei nichtgestillten Kindern - bei frühem Prophylaxebeginn in der Schwangerschaft (28. Schwangerschafts- woche) die Prophylaxedauer beim Neugeborenen ohne Wirksamkeitseinbuße kurz gehalten werden kann (drei Tage), während bei späterem Prophylaxebeginn (35. Woche) die Wirksamkeit durch eine längere Prophylaxe beim Kind (sechs Wochen) gesteigert wird. Die meisten Studien wurden mit ZidovudinMonotherapie durchgeführt. Andere Prophylaxeregime bestanden aus Zidovudin + Lamivudin und Nevirapin. Eine in Durban vorgestellte Studie vergleicht Stavudin-Monotherapie, Didanosin-Monotherapie und eine StavudinDidanosin-Kombination mit der Zidovudin-Monotherapie [Gray et al., TuOrB355].

\section{"Die Übertragungsrate kann durch eine antiretrovirale Be- handlung reduziert werden."}

Die Mütter erhielten in dieser Studie die Medikamente im Mittel etwa 30 Tage vor der Geburt, die mittlere Prophylaxedauer bei den Neugeborenen beträgt etwa sechs Wochen. Die "proof-of-concept"Studie ist mit etwas über 200 Teilnehmerinnen nur groß genug um festzustellen, ob die Wirksamkeit in derselben GröBenordnung liegt. Dies ist der Fall, die mittlere Übertragungsrate nach sechs Wochen bei den nichtgestillten Kindern liegt bei $3,6 \%$. Selbst wenn man den schlimmsten Fall annimmt und davon ausgeht, dass alle Kinder infiziert sind, die nicht zu Folgeuntersuchungen erschienen, läge die Übertragungsrate höchstens bei $9 \%$ und damit immer noch um mindestens die Hälfte niedriger als ohne Prophylaxe zu erwarten. Dies deutet darauf hin, dass die verschiedenen Nukleosidanaloga in diesem Zusammenhang eine vergleichbare Wirksamkeit aufweisen und es sich nicht um einen Zidovudin-spezifischen Effekt handelt.

Von besonderer Bedeutung sind die Ergebnisse, die mit dem nichtnukleosidischen Reverse-Transkriptase-Inhibitor (NNRTI) Nevirapin erzielt werden. Die NNRTI entfalten im Unterschied zu den Nukleosidanaloga, die erst innerhalb der Zelle zu dem letztlich wirksamen Triphosphat phosphoryliert werden müssen, ihre Wirkung ohne vorherige Verstoffwechslung sofort. Da Nevirapin bei erstmaliger Gabe seine eigene Verstoffwechslung induziert, wird die Substanz zu therapeutischen Zwecken einschleichend dosiert. Mit einer Initialdosis von $200 \mathrm{mg} / \mathrm{Tag}$ wird beim Beginn einer Therapie derselbe Wirkspiegel erreicht wie bei längerer Gabe mit einer Tagesdosis von $400 \mathrm{mg}$. Zur Verhinderung der Mutter-Kind-Übertragung wurde Nevirapin in der HIVNET 012Studie in Uganda in einer einmaligen Dosis von $200 \mathrm{mg}$ bei der Schwangeren möglichst früh nach Beginn der Wehen und in einer Einmaldosis von $2 \mathrm{mg} / \mathrm{kg}$ beim Neugeborenen innerhalb der ersten zwei bis drei Tage nach der Geburt eingesetzt. Damit wird, im Vergleich zu einer ultrakurzen Zidovudin-Prophylaxe (Beginn bei Einleitung der Geburt, einwöchige Behandlung des Neugeborenen), eine deutliche Reduktion der Übertragungsrate erreicht (Übertragungsrate bei gestillten Kindern nach 14 bis 16 Wochen $13,1 \%$ im Nevirapin- und 22,1\% im Zidovudin-Arm). Der Unterschied bleibt auch nach zwölf Monaten noch in dieser Größenordnung bestehen: $15,7 \%$ Infektionsrate im NevirapinArm gegenüber $24,1 \%$ im ZidovudinArm. 80,5\% der Kinder im NevirapinArm überlebten das erste Lebensjahr ohne sich mit HIV infiziert zu haben, $71,2 \%$ der Kinder im Zidovudin-Arm. Schwerwiegende medikamentenbedingte Nebenwirkungen wurden bislang nicht registriert [Owor et al., LbOr1]. Eine zweite Studie mit Nevirapin, die süd- 
afrikanische SAINT-Studie, vergleicht die Nevirapin-Prophylaxe mit einer Kurzzeit-Zidovudin/Lamivudin-Kombinationsprophylaxe (Beginn auch hier so früh wie möglich nach Beginn der Wehen und während der ersten Lebenswoche Medikamentengabe sowohl bei der Mutter wie auch beim Kind). Die Gabe der ersten Medikamentendosis erfolgte in der Klinik vor der Geburt. Bei mehr als 1300 teilnehmenden, gleichmäßig auf die beiden Arme verteilten Schwangeren lassen sich sechs bis acht Wochen nach der Geburt keine signifikanten Unterschiede hinsichtlich Übertragungsraten und Mortalität feststellen (zwischen 12,5 und 14,3\%). Die Medikamenteneinnahme erfolgte bei immerhin einem Viertel der Frauen erst sehr spät, d. h. innerhalb von zwei Stunden vor der Entbindung. Eine weitere Reduktion der Übertragungsrate ließe sich vermutlich dadurch erreichen, dass die Schwangere Medikamente mit nach Hause bekommt mit der Instruktion, diese bei Beginn der Wehen einzunehmen. Etwa 40\% der Kinder in beiden Armen werden gestillt, die anderen erhalten künstliche Babynahrung [Moodley et al., LbOr2].

\section{"Als besonders wirksam bei der Reduzierung der Übertra- gungsrate erwiesen sich die nichtnukleosidischen Reverse- Transkriptase-Inhibitoren (NNRTI)."}

Der große Vorteil der Nevirapin- verglichen mit einer Zidovudin- oder Zidovudin/Lamivudin-Kurzzeitprophylaxe ist die nochmals deutlich einfachere Handhabung (zwei Dosen gegenüber 25 bis 30 Dosen) und die weiter reduzierten Kosten (4 US \$ für die beiden Dosen Nevirapin). Auch kann die Nevirapin-Gabe unauffälliger erfolgen als die über einen längeren Zeitraum erforderliche Gabe von Nukleosidanaloga, die eher Erklärungsbedarf auslöst - ein nicht zu unterschätzender Vorteil, wenn die Familie und/oder der Partner/Kindesvater von der Infektion der Mutter nichts erfahren soll. Eine kritische Frage für alle Interventionsstrategien in Entwicklungsländern, die auf der perinatalen Medikamentengabe beruhen, ist die Dauerhaftigkeit des Erfolges bei gestillten Kindern und die Frage der Morbidität und
Mortalität bei Ersatz des Stillens durch künstliche Babynahrung. Für die einzuschlagende Strategie ist von entscheidender Bedeutung, ob die Reduktion der Übertragungsrate durch Medikamente durch eine höhere Übertragungsrate beim Stillen wieder aufgehoben wird. Bislang ist die Nachbeobachtungsdauer nur bei einem Teil der Studien lang genug, um dies beurteilen zu können und unglücklicherweise sind die vorliegenden Ergebnisse widersprüchlich. In zwei westafrikanischen Studien, in denen $\mathrm{Zi}$ dovudin ab der 36. Schwangerschaftswoche bis zur Geburt gegeben wurde und in denen fast alle Kinder gestillt wurden, bleibt der Unterschied zwischen Zidovudin- und Plazebo-Arm mit $8,4 \%$ nach 24 Monaten nahezu konstant (21,9\% Infektionsrate vs. 30,3\%). In der vierarmigen internationalen PETRA-Studie (Zidovudin+Lamivudin in unterschiedlicher Dauer verglichen mit Plazebo) ist der Unterschied zwischen dem zunächst wirksamsten Arm (ZDV+Lamivudin ab der 36 SSW. bis Ende der ersten Lebenswoche) und Plazebo nach 18 Monaten statistisch nicht mehr signifikant $(21,3 \%$ vs. $26,8 \%$ kombinierte Übertragungsund Mortalitätsrate) [Gray et al., LbOr5]. In der PETRA-Studie werden etwa 70\% der Kinder gestillt. Eine plausible Erklärung für die unterschiedlichen Befunde gibt es noch nicht. Es ist nicht ganz auszuschließen, dass die Hinzunahme von Lamivudin zum Prophylaxeregime paradoxerweise eher schadet als nutzt, aber eine detailliertere Analyse der Ergebnisse kann auch noch andere Erklärungen zutage fördern.

\section{Offene Fragen}

Die intrauterine Übertragungsrate, die auf Grundlage des positiven Virusnachweises beim Neugeborenen unmittelbar nach der Geburt bestimmt wird, liegt in den meisten afrikanischen Studien in Größenordnungen zwischen 6 und 10\%. In den Industriestaaten liegt dieser Wert auch bei Kurzzeitprophylaxen (Beginn 32. bis 36. SSW.) deutlich niedriger. Da der intrauterine Übertragungsmechanismus noch nicht geklärt ist, kann über die Gründe hierfür bislang nur spekuliert werden. Möglicherweise spielen eine höhere Rate aufsteigender Infektionen und Begleiterkrankungen wie die Malaria eine Rolle. Ein erheblicher Teil der perinatalen Übertragung findet kurz vor und unter der Geburt statt. Auch hier ist der genaue Übertragungsweg unklar. In Frage kommt z. B. Schlucken von virushaltigem Fruchtwasser. Mütterliche Zellen könnten unter dem Einfluss der bei Wehenbeginn sich erheblich verstärkenden und verändernden lokalen $\mathrm{Zy}$ tokinausschüttung vermehrt Virus produzieren, welches in das Fruchtwasser diffundiert. Ein anderer Weg wäre die Schleimhautkontamination beim Kind durch mütterliches Blut und/oder andere virushaltige Körperflüssigkeiten auf dem Weg durch den Geburtskanal. Die Möglichkeit der postnatalen Übertragung durch Muttermilch ist unstrittig. Muttermilch kann freies Virus und virusinfizierte Zellen enthalten. Der Virusgehalt kann zwischen beiden Brüsten unterschiedlich sein, d. h. lokale Faktoren (z. B. Mastitis) [Willumsen et al., TuPeC3448] können die Viruslast der Milch beeinflussen. Interessanterweise gibt es zwei Studien die nahe legen, dass exklusives Stillen in den ersten sechs Monaten zu deutlich geringeren Übertragungsraten führt als eine Ernährung, bei der zugefüttert wird [Taren et al., MoPeB220o und Coutsoudis et al., LbOr6]. Das Zufüttern von Brei, Säften, Zuckerwasser etc. ist zumindest in Afrika weit verbreitet und wurde bisher bei Mutter-Kind-Übertragungsstudien nicht weiter beachtet. In der südafrikanischen Studie war im Alter von sechs Monaten kein Unterschied in der Übertragungsrate zwischen den mit künstlicher Babynahrung ernährten und den ausschließlich gestillten Kindern feststellbar $(19,4 \%)$, dagegen wurde eine deutlich höhere Übertragungsrate $(26,1 \%)$ bei den gemischt ernährten Kindern registriert. Eine mögliche, nicht unplausible Erklärung für dieses Phänomen könnte darin bestehen, dass Muttermilch die Reifung der kindlichen Darmschleimhaut beschleunigt und eine Zufütterung durch vermehrte Zuführung von Fremdantigenen und Allergenen zu einer vermehrten Stimulation des intestinalen Immunsystems führt, welche das Risiko einer HIV-Übertragung vergrößert [4].

\section{"Die Zufütterung sollte 'bei Übertragungsstudien in Afrika berücksichtigt werden, da ihre Rolle bislang noch ungeklärt ist."}


Bei beiden Untersuchungen, bei denen exklusives Stillen mit gemischter Ernährung verglichen wurde, war keine medikamentöse Prophylaxe erfolgt. Entsprechende Beobachtungen aus Studien, in denen die Mutter-Kind-Übertragungsrate durch perinatal verabreichte Medikamente reduziert wird, liegen bislang nicht vor, so dass unklar ist, ob Kinder, bei denen durch Medikamente eine Übertragung verhindert wird, bei ausschließlichem Stillen ebenfalls vor einer Infektion geschützt sind. Sicher ist dies nicht, zumal in einer anderen Untersuchung festgestellt wurde, dass ein Teil der Kinder HIV-infizierter Mütter, offenbar induziert durch eine intrauterine Virusexposition, eine HIV-spezifische zelluläre Immunreaktion entwickelt, die sie anscheinend auch vor einer postnatalen Infektion schützt [Kuhn et al., TuOrA282]. Wenn durch die medikamentöse Prophylaxe Kinder ohne eine solche zelluläre Immunität vor einer Infektion geschützt werden oder durch eine intensive Prophylaxe ein geringerer Anteil der Kinder eine solche zelluläre Immunantwort ausbildet, könnten diese Kinder besonders empfänglich für eine Infektion über Muttermilch sein.

\section{Von der Forschung in die Praxis - über die Schwierigkeiten bei der Implementierung}

Nach Veröffentlichung der ersten Studienergebnisse zur Wirksamkeit von Zidovudin-Kurzzeitprophylaxen zur Reduktion der Mutter-Kind-Übertragungsrate 1998/99 wurde in einer Reihe von Entwicklungsländern mit Machbarkeitsstudien zur Implementierung entsprechender Angebote begonnen. In Nordostthailand wurde beispielsweise im Juli 1998 das Angebot einer Zidovudin-Kurzzeitprophylaxe für HIV-infizierte Schwangere etabliert. In der Region nehmen 99\% der Schwangeren Vorsorgeuntersuchungen wahr. In der Zeit zwischen Juli 1998 und März 2000 wurden durchschnittlich 69\% der Schwangeren auf HIV untersucht. Der Anteil stieg im Verlauf von $60 \%$ auf $80 \%$. Probleme gab es anfangs bei der Testberatung wegen mangelnder Qualifikation des Personals, mit der Verfügbarkeit von Tests in allen Krankenhäusern und der Verfügbarkeit des Testergebnisses, vor allem wenn Testung und Geburt nicht im selben Krankenhaus erfolgten. Die HIV-
Prävalenz lag bei o,9\%, der Anteil der HIV-positiven Schwangeren, die eine Zidovudin-Kurzzeitprophylaxe erhielten, betrug 69\%, die Compliance war mit $87 \%$ zufriedenstellend. Gründe dafür, dass die Zidovudin-Prophylaxe nicht begonnen wurde, waren verspätete Inanspruchnahme der Schwangerschaftsvorsorge, Frühgeburt, Wechsel des Aufenthaltsortes in eine andere Region und familiär bedingte Vorbehalte. Die Übertragungsrate sank auf 9,4\% (gesamt; 8,2\% unter ZDV-Prophylaxe). Infizierte Schwangere erhalten künstliche Babynahrung und der Verzicht auf Stillen bereitet den betroffenen Frauen offenbar keine unüberwindbaren sozialen Probleme [Kanshana et al., WeOrC553]. Zum Erfolg des Programms tragen bei die funktionierende Logistik und das Kommunikationssystem zwischen den verschiedenen beteiligten Gesundheitseinrichtungen sowie die vorbereitenden und begleitenden Trainingsmaßnahmen für das medizinische Personal.

Etwas anders sehen die Erfahrungen in Afrika aus. In Botswana, dem Land mit der weltweit höchsten HIVPrävalenz unter Erwachsenen (bei Schwangerschaftsvorsorgeuntersuchungen wird im Landesdurchschnitt eine HIV-Prävalenz von $36 \%$ gemessen) und einer vergleichsweise noch guten medizinischen und sanitären Infrastruktur wurde 1999 mit einem landesweiten $\mathrm{Zi}$ dovudin-Prophylaxeprogramm begonnen. In Botswana waren zu diesem Zeitpunkt $15 \%$ aller Neugeborenen HIV-infiziert, und $70 \%$ aller kindlichen Todesfälle waren HIV-bedingt. Das Programm sieht ein Beratungs- und Testangebot für alle Schwangeren vor, im Falle einer HIV-Infektion können sie ab der 34 . Schwangerschaftswoche bis zur Entbindung Zidovudin erhalten, das Kind kann während des ersten Lebensmonats pro-

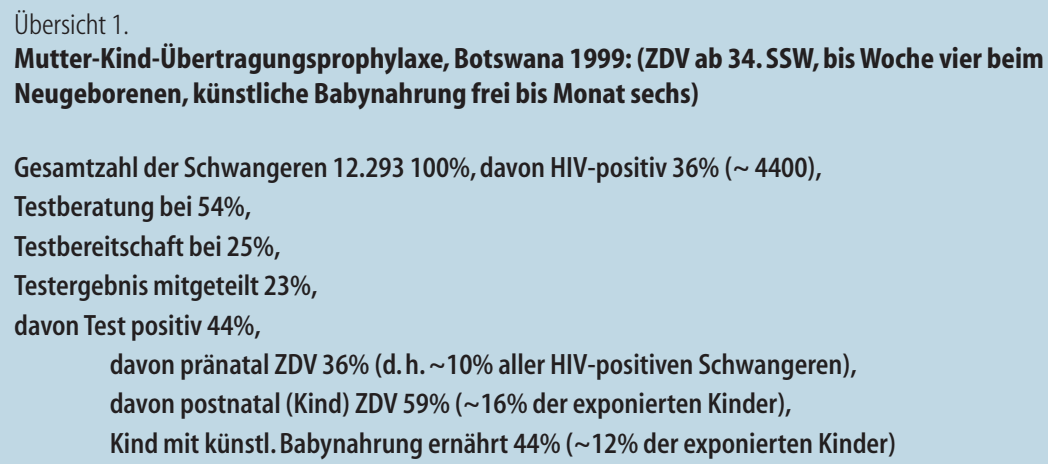

phylaktisch behandelt werden. Künstliche Babynahrung wird für die ersten sechs Lebensmonate zur Verfügung gestellt. Bisher wurden seit Beginn des Programms im ganzen Land $\mathbf{1 2 . 2 9 3}$ Schwangere in den Kliniken betreut. Eine HIV-Testberatung erhielten 6698 (54\%), davon waren 3101 (45\%) bereit, sich testen zu lassen. Ein Testergebnis wurde 2824 Schwangeren mitgeteilt, davon waren 1238 (44\%) HIV-positiv. Von diesen nahmen nur 448 vor der Entbindung Zidovudin, die Zahl der Kinder, die nach der Geburt mit Zidovudin behandelt wurden, betrug 726. 546 Kinder wurden mit künstlicher Babynahrung gefüttert. Das bedeutet, dass bislang nur etwa $10 \%$ der in Frage kommenden Schwangeren mit Zidovudin behandelt wurden (siehe Übersicht 1) [Mazhani et al., WeOrC550].

Das ernüchternde Fazit: es reicht nicht aus, die Medikamente zur Verfügung zu stellen, auch die Beratungskapazität und -qualität muss verbessert werden, und neben den Schwangeren müssen die Gesellschaft als Ganzes und vor allem die Familien und Partner der Frauen in die Aufklärung mit einbezogen werden, da die Frauen ihre Entscheidungen nicht im luftleeren Raum fällen. Etwas besser sehen die Ergebnisse einer Pilotstudie in einer urbanen Region in Rwanda aus. Das Angebot dort beinhaltet Testberatung, Test, Screening auf Syphilis, Malariaprophylaxe, Eisen- und Folatsubstituierung, bei positivem HIVTest Zidovudin-Gabe ab der 36. Schwangerschaftswoche bis Ende der ersten Lebenswoche sowie künstliche Babynahrung für die ersten sechs Monate. Von April bis Dezember 1999 wurden 1113 Schwangere betreut, davon wurden 795 ( $71 \%)$ auf HIV getestet, die HIV-Prävalenz betrug 22,3\%. Die Frauen wurden ermutigt, ihre Partner mit in die Bera- 
tung und zum Test zu bringen. Nur 6\% der Partner nahm dieses Angebot wahr. 163 von 172 HIV-positiven Schwangeren erschienen nach dem Test wieder, um das Ergebnis zu erfahren, davon begannen 124 mit der Zidovudinbehandlung. Während der Geburt erhielten noch 95 Frauen das Medikament, $86 \%$ der Kinder wurden mit künstlicher Babynahrung ernährt [Karita et al., WeOrC551]. Deutlich größere Implementierungsprobleme zeigen sich in einer ländlichen Region in Kenia. Die durchschnittliche HIV-Prävalenz bei Schwangeren in der Versuchsregion liegt dort bei $26,2 \%$ mit lokalen Schwankungen zwischen 8,3 und 33,3\%. 216 Schwangere (von 825) wurden dort bislang positiv getestet, davon waren $92 \mathrm{zu}$ einer prophylaktischen Zidovudinbehandlung nicht bereit. Eine Zidovudingabe während der Entbindung war für 89 Mütter nicht möglich, da sie zu Hause und nicht in der Klinik entbunden wurden. Künstliche Babynahrung konnte nicht kostenlos zur Verfügung gestellt werden und Zugang zu hygienisch einwandfreiem Wasser war für die Mehrheit der Frauen nicht gewährleistet. Alle Mütter stillten daher ihre Kinder. Bei den Müttern, die Zidovudin erhalten hatten, lag die Übertragungsrate bei $14,6 \%$, bei den nichtbehandelten Müttern bei $42 \%$. Die Nachuntersuchung ergab jedoch auch, dass ca. 20\% der behandelten Frauen nach der Geburt geschieden worden war, eine mögliche Folge des Bekanntwerdens ihres positiven HIV-Status? [Songok et al., WeOrC552]

In den Pilot- und Implementierungsstudien in Afrika zeigen sich folgende Probleme: Mangelnde Qualifikation der Testberater, fehlende Testmöglichkeiten, keine kontinuierliche Betreuung der Schwangeren, oftmals nur einmaliger oder unregelmäßiger Kontakt, Unsicherheiten bei der Berechnung des Gestationsalters, Angst vor dem Test bzw. einem positiven Testergebnis und den daraus sich möglicherweise ableitenden Konsequenzen für die Partnerschaft oder die Unterstützung durch die Familie, Angst vor Enthüllung des positiven HIV-Status bei regelmäßiger Einnahme von Medikamenten oder bei Verzicht auf Stillen. Künstliche Babynahrung, wenn sie nicht kostenlos oder stark subventioniert zur Verfügung gestellt wird, ist für die meisten Frauen zu teuer. Ein Verzicht auf Stillen ist meist erklärungsbedürftig. Nicht nur die Mütter, sondern auch die Väter und vielerorts auch das medizinische und paramedizinische Personal müsste über die Risiken des Stillens aufgeklärt werden [Chopra et al., MoOrD203; Tlou et al., MoOrD204; Desclaux et al., MoOrD205]. Falls sich die Befunde zur gemischten Ernährung und zum ausschließlichen Stillen in den ersten Monaten bestätigen sollten, könnte daraus ein weiteres Problem resultieren. Bei Verzicht auf Stillen müsste eine ausreichende und ununterbrochene Versorgung mit künstlicher Babynahrung gewährleistet sein. Falls ausschließliches Stillen in den ersten Lebensmonaten doch akzeptabel sein sollte, müsste ein Wechsel der Strategie mit scheinbar einander widersprechenden Botschaften (Infektionsgefahr durch Muttermilch, aber ausschließliche Ernährung durch Muttermilch mit geringerem Risiko als gemischte Ernährung) sowohl dem Personal als auch den Müttern plausibel erklärt werden [Chopra et al., MoOrD206].

Die mit Dauer und Sichtbarkeit der Zidovudingabe verbundenen Nachteile können mit der Nevirapingabe weitestgehend umgangen werden. Unabhängig davon, ob und wie das Problem der Übertragung durch Muttermilch angegangen werden kann, sprechen die meisten bisher vorliegenden Befunde dafür, dass die Reduktion der Übertragungsrate auch bei gestillten Kindern Bestand hat. Die Verträglichkeit ist exzellent. Daher spricht nichts dagegen, sofort mit der Implementierung dieser Maßnahme zu beginnen. Die Herstellerfirma Boehringer-Ingelheim hat darüber hinaus zugesagt, Entwicklungsländern die Substanz über die kommenden fünf Jahre kostenlos zur Verfügung zu stellen. Einen kleinen, aber bislang nicht ins $\mathrm{Ge}$ wicht fallenden Unsicherheitsfaktor stellt die Beobachtung dar, dass bereits durch die extrem kurze Prophylaxe eine Resistenzbildung gegen Nevirapin bei ca. 20\% der untersuchten Frauen (drei von 14) nachgewiesen werden kann. Die Resistenzmutante persistiert aber zumindest nicht als dominierende Virusvariante, so dass fraglich ist, ob dies hinsichtlich der Wirksamkeit bei zukünftigen Schwangerschaften klinisch relevant ist [5]. Es würde dann allerdings an Relevanz gewinnen, wenn antiretrovirale Kombinationstherapien bei HIV-Infi- zierten in Entwicklungsländern in größerem Umfang möglich werden.

\section{Politisch-ethische Konsequenzen}

Die Reduzierung der Mutter-KindÜbertragungsrate stellt den ersten Bereich dar, in dem die in den Industriestaaten entwickelten Medikamente in größerem Umfang in Entwicklungsländern eingesetzt werden könnten. Die Implementierung entsprechender Programme stellt insofern einen Präzedenzfall dar, durch den auch über kurz oder lang die Frage des therapeutischen Einsatzes antiretroviraler Medikamente in Entwicklungsländern auf die Tagesordnung gesetzt wird. Um einen optimalen Erfolg der Interventionsmaßnahme zu gewährleisten, müssen die Schwangerenbetreuung verbessert, Test- und Beratungsangebote mit ausreichend qualifiziertem Personal integriert und eine weitergehende psychosoziale Betreuung der Mütter aufgebaut werden. Wenig durchdacht erscheint in diesem Zusammenhang eine von der Regierung Botswanas geplante Gesetzgebung, die HIVpositive Personen verpflichten soll, ihren HIV-Status dem jeweiligen Sexualpartner mitzuteilen. In der gegenwärtigen Situation würde dies Mütter eher davon abschrecken, einer HIV-Testung zuzustimmen. Weiterhin erforderlich sind eine funktionierende Infrastruktur für die landesweite Verteilung der Medikamente. Die dafür erforderlichen Investitionen in Infrastruktur vermindern gleichzeitig die Barrieren, die einem therapeutischen Einsatz antiretroviraler Medikamente im Wege stehen. Die Erfahrung in Pilotprogrammen zeigt, dass ein solches Prophylaxe-, Test- und Beratungsangebot zu einer aktiveren Auseinandersetzung der Menschen mit dem Problem AIDS beiträgt und den Panzer aus Verleugnung und Apathie aufzubrechen in der Lage ist, insbesondere wenn sich Aufklärungs- und Informationskampagnen zu diesem Angebot nicht nur an Schwangere richten, sondern an die ganze Bevölkerung.

Die südafrikanische Regierung reagiert bisher mit Zurückhaltung und immer neuen Vorwänden auf die wissenschaftlich eindeutige Datenlage. Eine landesweite Implementierung der Zidovudinprophylaxe wurde unter dem Vorwand verweigert, die Substanz sei zu to- 
xisch. Die Nevirapin-Studienergebnisse aus Uganda sollten erst einmal durch eine südafrikanische Studie bestätigt werden. Nun, da diese Studie zu vergleichbaren Ergebnissen geführt hat, wird nach neuen Vorwänden gesucht. Auf die Ankündigung von Boehringer-Ingelheim, Entwicklungsländern Nevirapin zunächst für die kommenden fünf Jahre kostenlos zur Verfügung zu stellen, reagierte die Konferenz der Gesundheitsminister des südlichen Afrikas mit einer Presseerklärung, in der sich die Minister darüber beklagten, dass sie zuvor von diesem Angebot nicht informiert worden seien. Die Gründe für das Hinauszögern von Programmen zur Reduktion der Mutter-Kind-Übertragung sind schwer nachvollziehbar, sie könnten aber u. a. auf der Angst vor weiterführenden Forderungen beruhen. In der Tat drängt sich natürlich die Frage auf, warum HIV-infizierte Schwangere antiretrovirale Medikamente nur erhalten sollen, um ihre Kinder vor einer Infektion zu schützen, nicht jedoch, um selbst davon zu profitieren. Auch ist das Argument nicht von der Hand zu weisen, dass die Probleme nur verlagert werden, wenn HIV-infizierte Frauen mehr gesunde Kinder bekommen, die nach dem Tod der Mutter nur das ohnehin kaum zu bewältigende Problem der AIDS-Waisen vergrößern.

\section{AIDS-Waisen - eine verlorene Generation?}

Anders als praktisch alle anderen Krankheiten und Naturkatastrophen fordert die AIDS-Epidemie ihre Opfer in erster Linie in der Generation der für die Ernährung der Familien zuständigen jungen Erwachsenen. Das Massensterben in der Elterngeneration lässt Kinder und Großeltern zurück. Weltweit haben bislang bereits mehr als 13 Mio. Kinder Mutter, Vater oder beide Eltern durch AIDS verloren (95\% davon leben in Afrika) (Abb. 16).

Bis zum Jahr 2010 soll die Zahl der Waisenkinder nach einer Studie der USamerikanischen Entwicklungshilfeorganisation USAID in den 34 am stärksten von AIDS heimgesuchten Ländern auf 44 Millionen steigen. Bei $68 \%$ von ihnen werden die Eltern an AIDS gestorben sein. Vor AIDS waren etwa $2 \%$ der Kinder in Entwicklungsländern Waisen. In den acht am stärksten betroffenen Ländern Afrikas ist der Prozentsatz der Waisen unter den unter 15-jährigen Kindern laut USAID bereits auf 20 bis $35 \%$ angestiegen. USAID bezeichnet dabei Kinder, die ihre Mutter, ihren Vater oder beide Eltern verloren haben als Waisen, während nach der UNAIDS-Definition Kinder, die nur ihren Vater verloren haben,

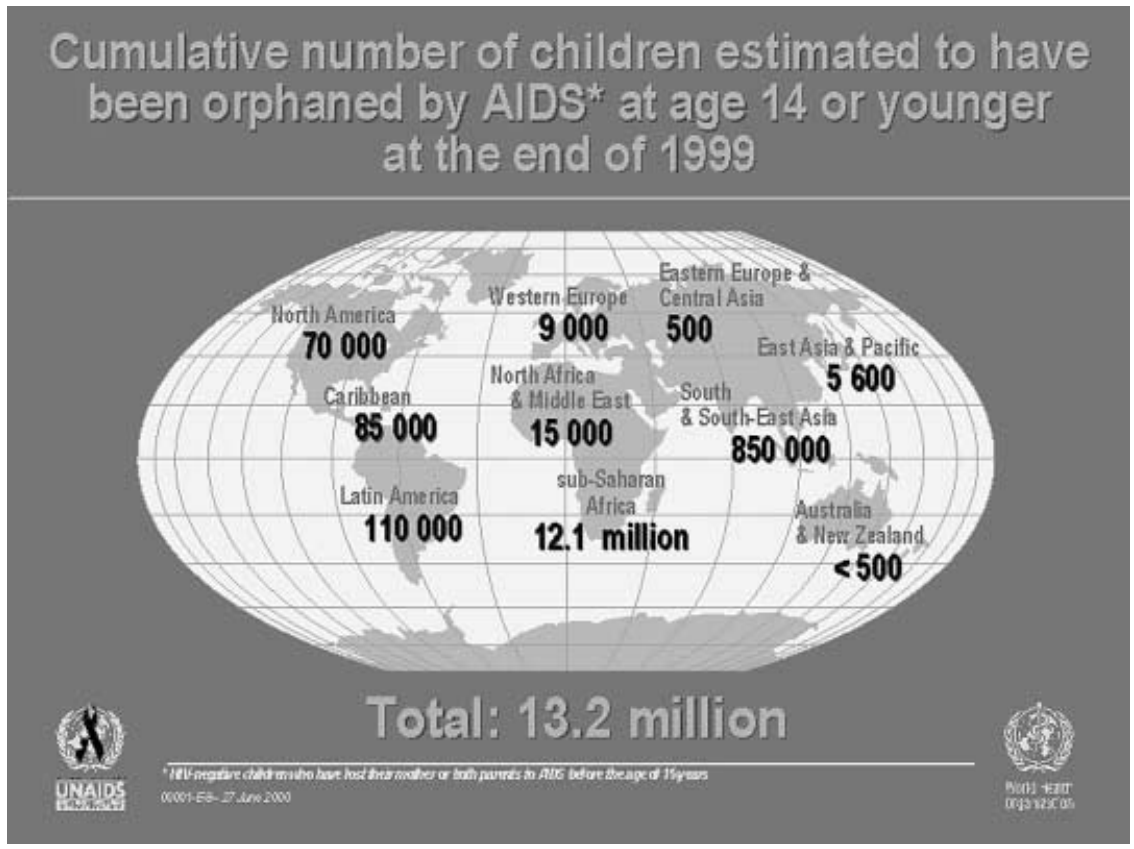

Abb. $16 \Delta$ Kumulierte Zahl und geographische Verteilung der Kinder, die durch AIDS bis Ende 1999 ihre Mutter oder beide Eltern verloren haben (Quelle: UNAIDS)

noch nicht als Waisen zählen. Oft hat in der Tat der Verlust nur eines Elternteils nahezu dieselben verheerenden Auswirkungen wie der Verlust beider Eltern. Heiratet beispielsweise die Witwe erneut, weigert sich der neue Ehemann nicht selten, für die Kinder aus erster Ehe zu sorgen. Traditionelle Bewältigungsstrategien wie die Aufnahme bei Verwandten sind längst nicht mehr in der Lage, das Problem aufzufangen. Eine detaillierte Untersuchung in einer ländlichen, neun Dörfer umfassenden Region Ugandas identifizierte in diesem Gebiet 279 Kinder, die nach der konservativeren UNAIDS-Definition (Verlust der Mutter oder beider Eltern) als Waisen gezählt würden. Die tatsächliche Zahl der Kinder, die durch AIDS wesentlich beeinträchtigt waren, sei es durch Verlust des Vaters, sei es durch Verarmung von Haushalten, die zusätzlich für eine größere Zahl von Waisen zu sorgen hatten, betrug 1386, d. h. mehr als das vierfache.

Großmütter sehen sich plötzlich gezwungen, für ein Dutzend oder mehr Enkelkinder zu sorgen, von Kindern geführte Haushalte entstehen, in denen Achtjährige für ihre jüngeren Geschwister sorgen müssen. Die Möglichkeiten zum Gelderwerb beschränken sich dabei in der Regel auf Kleinstgewerbe wie Schuhputzen oder Zigarettenverkauf, die kaum genügend Geld einbringen, um eine Person zu ernähren. Neben dem Verlust ihrer Eltern müssen die Kinder oft auch noch mit dem Stigma leben, dass ihre Eltern an AIDS verstorben sind und der Kontakt mit ihnen gemieden wird, weil sie ebenfalls als infiziert gelten. Durch Verlust der Eltern und damit auch der Haupteinkommensquelle ist die Gefahr von Mangelernährung, Krankheit und Missbrauch durch Erwachsene größer. Ihre Ausbildung ist schlechter, weil sie häufig darauf angewiesen sind, Geld zu verdienen anstatt in die Schule zu gehen. All diese Nachteile und Widrigkeiten erhöhen das Risiko, dass sie sich später auch irgendwann mit HIV infizieren, wenn sie nicht schon über ihre Mutter infiziert wurden [6]. Überall in den betroffenen Ländern gründen sich in den Gemeinden und Kommunen Initiativen, die mit verschiedenen Mitteln versuchen, die Krise in den Griff zu bekommen und den Waisen ein menschenwürdiges Leben zu ermöglichen. Gemeinschaftsküchen und Tagesbetreuungseinrichtungen, Verteilung 
von Lebensmitteln und Kleidung, staatliche Unterstützungszahlungen und kostenloser Schulbesuch in den reicheren Ländern, neue Gesetze, die Waisenkinder vor Übervorteilung und Ausbeutung besser schützen sollen, "Neugründung" von Familien, bei denen Waisenkinder mit kinderlosen, meist älteren Erwachsenen einen neuen Haushalt gründen, sind einige der vielfältigen Versuche, mit den Problemen umzugehen (UNICEF: Children orphaned by AIDS - Front-line responses from eastern and southern Africa).

\section{Warum verläuft die HIV/AIDS- Epidemie in Afrika so viel schwerer als in anderen Teilen der Welt?}

Nirgendwo anders auf der Welt hat sich die HIV-Epidemie bisher so dramatisch ausgebreitet wie in Schwarzafrika. Zwar werden in bestimmten Teilpopulationen (Hämophile, homosexuelle Männer in Metropolen, i.v.-Drogenkonsumenten) auch in den Industriestaaten sehr hohe HIV-Prävalenzen von bis $\mathrm{zu} 50 \%$ erreicht, regional sogar noch mehr, aber HIV-Prävalenzen in der erwachsenen Gesamtbevölkerung von 20 bis $35 \%$, wie sie in Ost- und Südafrika mittlerweile registriert werden, sind bislang in anderen Kontinenten nicht beobachtet worden. Das dramatische Ausmaß der Epidemie in Afrika hat eine Reihe von Ursachen. Ein sicherlich nicht zu vernachlässigender Faktor ist der Zeitfaktor. Alles spricht dafür, dass HIV ursprünglich eine Zoonose war, d. h. dass das Virus von Affen auf den Menschen übertragen wurde. Betrachtet man die Verbreitung der Affenimmundefizienzviren, der nächsten Verwandten von HIV, so liegt der Ursprung der HIV-1Epidemie wahrscheinlich in Zentralafrika, der Ursprung der HIV-2-Epidemie in Westafrika. Verwandtschaftsanalysen unter Zuhilfenahme einer "molekularen Uhr" datieren den Ursprung der HIV-1M-Gruppe auf die dreißiger Jahre des 20. Jahrhunderts [Vandamme et al., MoOrA163]. Es lässt sich zwar wissenschaftlich nicht mit Sicherheit ausschließen, dass Theorien wie die Entstehung von HIV durch SIV-kontaminierte orale Polioimpfstoffe zutreffen könnten, aber wahrscheinlicher sind andere Szenarien. So ist vorstellbar, dass sich - ähnlich wie beim Ebolavirus, immer wieder
Übertragungen auf den Menschen ereigneten, die aber Jahrhunderte lang in epidemiologischen Sackgassen endeten, weil das bei solchen Gelegenheiten übertragene Virus entweder für den Menschen nicht pathogen genug war und/oder sich keine ausreichenden Weiterverbreitungsmöglichkeiten in der menschlichen Population ergeben hatten. In der Kolonialzeit kamen dann möglicherweise mehrere Faktoren zusammen, die dem in seinem natürlichen Wirt apathogenen Schimpansen-SIV die Metamorphose in das menschenpathogene HIV ermöglichten:

D ein Anstieg des Expositionsrisikos durch Maßnahmen, die zu einer $\mathrm{Zu}$ nahme der Jagd auf "Buschfleisch" führten, wie Requirierung von Dorfbewohnern zu Zwangsarbeit, Verfügbarkeit von Feuerwaffen für die Jagd u. ä.,

D eine Zunahme der Übertragungsmöglichkeiten von Mensch zu Mensch, sowohl auf sexuellem Wege (z. B. durch Zwangsarbeit für Infrastrukturprojekte, verbunden mit Prostitution) als auch durch medizinische Maßnahmen (Massenimpfungen z. B. gegen Pocken unter Bedingungen, die eine Übertragung von Infektionserregern ermöglichte, massenhaft durchgeführte intravenöse Behandlungen z. B. gegen die Schlafkrankheit unter Verwendung mangelhaft sterilisierter Spritzen),

D eine Begünstigung der Adaptation des Schimpansenvirus an den Menschen durch "serielle Passage" über mehrere menschliche Wirte, vor allem durch die oben angeführten verbesserten Übertragungsmöglichkeiten. Durch serielle Passagen in einem neuen Wirt kann die Virulenz eines Erregers gesteigert werden [7].

Unabhängig von der möglicherweise nie mehr einwandfrei zu klärenden Frage nach dem Ursprung der Epidemie muss sich HIV bereits in den sechziger und siebziger Jahren des 20. Jahrhunderts unbemerkt in einigen Regionen Zentralund Ostafrikas verbreitet haben. Solange die HIV-Prävalenz einen niedrigen einstelligen Prozentbereich nicht überstieg, gingen die Auswirkungen der Epidemie im "Hintergrundrauschen" ohnehin verbreiteter und aufgrund fehlender Medikamente und medizinischer Infrastruktur nicht therapierbarer Infekti- onskrankheiten unter. Selbst in den westlichen Industriestaaten konnten retrospektiv vereinzelte AIDS-Fälle in den sechziger und siebziger Jahren identifiziert werden, die aber, weil sie vereinzelt blieben, nicht als neue Krankheit erkannt wurden. Die weitere Ausbreitung begünstigende Verhältnisse wie Infrastrukturentwicklung (erhöhte Mobilität), Binnenmigration (Landflucht, Slumbildung, Prostitution), verstärkte Nutzung der westlichen "Schulmedizin" bei gleichzeitiger Vernachlässigung hygienischer Grundprinzipien (Bluttransfusionen, Injektionen) beschleunigten die Entwicklung. Eine katalysierende Funktion hatten vermutlich in einigen Ländern auch jahrelange bürgerkriegsähnliche Auseinandersetzungen einhergehend mit Vertreibungen, Vergewaltigungen, Auflösung sozialer Zusammenhänge etc. In Uganda fielen beispielsweise diesen inneren Auseinandersetzungen unter dem Diktator Idi Amin zwischen 1971 und 1979 ca. 300.000 Menschen zum Opfer, dem seinem Sturz folgenden Bürgerkrieg von 1981 bis 1986 eine weitere Million. Diese Ereignisse trugen zweifellos dazu bei, dass in Uganda zum Zeitpunkt, als die Epidemie durch Einsatz von HIV-Antikörperuntersuchungen sichtbar gemacht werden konnte, die weltweit höchsten Prävalenzraten gemessen wurden [8]. Nicht erklären kann der Zeitfaktor jedoch die rasante Ausbreitung, die HIV seit Mitte der achtziger Jahre von den damaligen Endemiegebieten aus genommen hat.

\section{"Die rasche Ausbreitung von HIV könnte u. a. auf unterschiedliche sexuelle Netzwerkstrukturen zurück- zuführen sein."}

Um die rasche Ausbreitung von HIV (Abb.17) zu erklären, müssten entweder erhebliche Unterschiede zwischen Afrika und dem Rest der Welt im individuellen Risikoverhalten vorliegen, oder unterschiedliche sexuelle Netzwerkstrukturen müssten die Dynamik der Epidemie erklären, oder es muss Faktoren geben, die die Infektiosität und Suszeptibilität für HIV spürbar erhöhen. Während Untersuchungen zum Sexualverhalten keine wesentlichen Unterschiede z. B. hinsichtlich der Partnerzah- 
len zwischen afrikanischen und westeuropäischen Ländern oder Nordamerika entdecken können, sind die errechneten Übertragungsraten pro Partnerschaft $(>0,6)$ [Auvert et al., MoPeC2475] höher als üblicherweise in Partnerstudien in den westlichen Industriestaaten. Dies könnte zumindest $\mathrm{z}$. T. erklärbar sein durch einen STD-Kofaktoreneffekt, der nach den vorliegenden Daten Infektiosität und Suszeptibilität erhöht. Sexuell übertragbare Infektionen sind in den meisten Entwicklungsländern deutlich stärker verbreitet als in den westlichen Industriestaaten. Als Hauptursache dafür werden die fehlenden bzw. zu teuren Diagnose- und Behandlungsmöglichkeiten und die mangelnde Aufklärung angesehen. Eine große randomisierte Vergleichsstudie in Tansania hatte ergeben, dass zumindest in einem frühen Stadium der HIV-Epidemie eine bessere Erkennung und Behandlung von sexuell übertragbaren Infektionen auch die HIV-Neuinfektionsrate um ca. 40\% reduzieren konnte. Eine Reihe von Untersuchungen konnte belegen, dass symptomatische Genitalinfektionen, z. B. durch Syphilis, Gonorrhoe, Chlamydien, Trichomonaden, Herpes simplex u. a. bei HIV-Infizierten zu einer erhöhten lokalen Produktion von HIV und Ausscheidung des Virus in den Genitalflüssigkei- ten führen. Durch Beeinträchtigung der Integrität der genitalen Schleimhäute und die höhere lokale Konzentration von Entzündungs- und möglichen Zielzellen für HIV können solche Infektionen auch die Suszeptibilität für eine HIV-Infektion erhöhen. So reduziert beispielsweise die Behandlung einer Zervizitis (ausgelöst durch Gonokokken, Chlamydien oder "unspezifisch") das Shedding von HIV in die Genitalsekrete um das 2,8-fache [McClelland et al., MoOrA231]. Auch die Behandlung einer vaginalen Candidose verringert in signifikantem Umfang (2,6-fach) das vaginale Shedding von HIV (durchschnittliche HIV-RNA-Konzentration sinkt von $2500 \mathrm{Kopien} / \mathrm{ml}$ auf $500 \mathrm{Kopien} / \mathrm{ml}$ ) [Wang et al., WePpA1367].

Ungeklärt ist, ob und wenn ja welche Rolle symptomlose oder symptomarme Genitalinfektionen für Infektiosität und Suszeptibilität spielen. In einer prospektiven, von den CDC in den USA durchgeführten Studie mit umfangreicher Diagnostik machten sich nur 45\% der sexuell übertragenen Infektionen bei Männern durch subjektiv empfundene Symptome bemerkbar, bei Frauen gar nur 23\% [Kamb et al., WePeC4399]. Diese Anteile dürften in Entwicklungsländern mindestens genauso hoch liegen. Zwar dürfte die Ausschüttung von Ent-

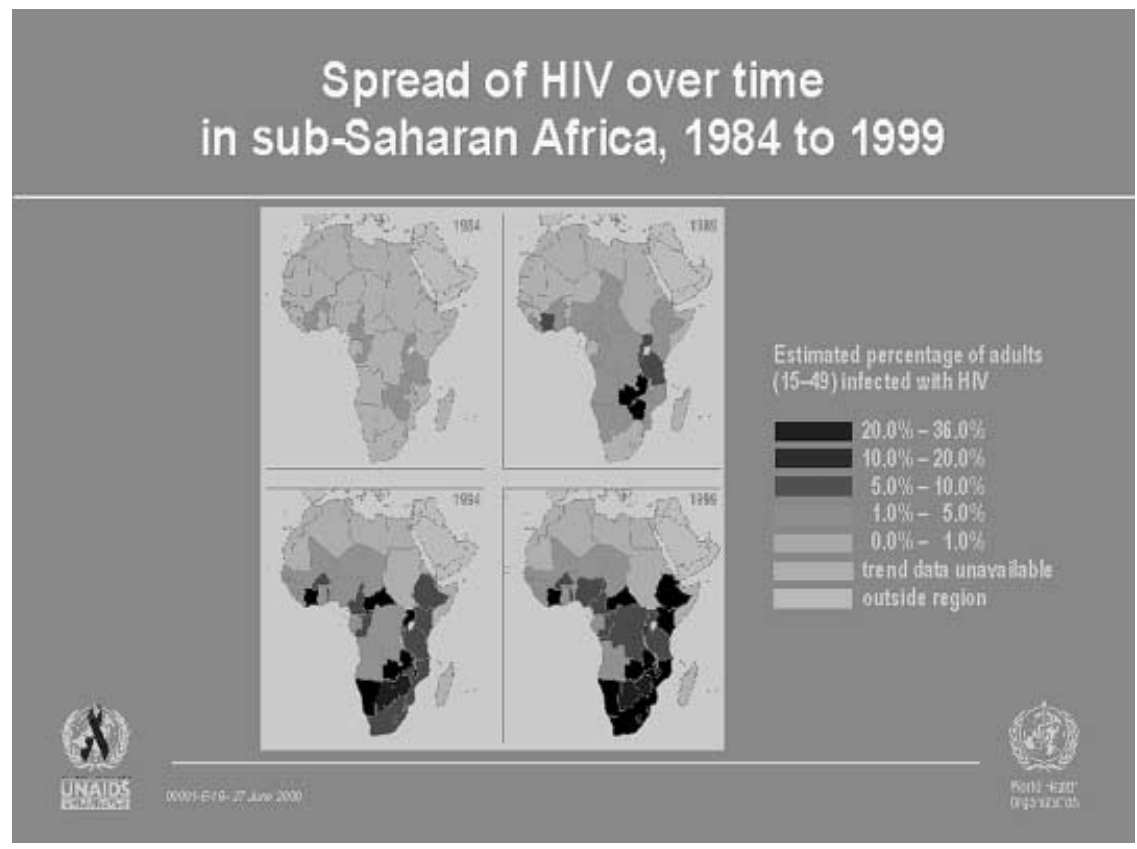

Abb. $17 \Delta$ Ausbreitung von HIV in Schwarzafrika seit 1984. Aufgrund der Konvertierung einer Farbabbildung in ein Schwarzweiß-Format ist der Unterschied zwischen den beiden höchsten Prävalenzstufen schwer zu erkennen: HIV-Prävalenzen in der erwachsenen Bevölkerung von über $20 \%$ werden seit 1994 in den südafrikanischen Staaten Botswana und Sambia erreicht zündungszytokinen bei symptomlosen Infektionen geringer sein und damit möglicherweise auch die Stimulation der lokalen HIV-Replikation, aber systematische Untersuchungen dazu liegen bislang nicht vor. Unklar ist auch, wie groß die Rolle der chronisch-rezidivierenden Herpes simplex Virus-Infektion als Kofaktor für die HIV-Übertragung ist. Als chronisch persistierende Virusinfektion ist Herpes simplex eine der möglichen Ursachen für Genitalgeschwüre, die als besonders effektiver Kofaktor für eine HIV-Übertragung gelten (Steigerung der Infektiosität bei Genitalgeschwüren, ausgelöst durch Syphilis, Haemophilus ducreyi oder HSV, um das 5-bis 10-fache) [Habbema et al., WePeC4385]. Gleichzeitig sind Häufigkeit und Schwere der HSV-Rezidive von der Immunkompetenz der infizierten Person abhängig, die durch die HIV-Infektion beeinträchtigt wird. Hier ist ein sich gegenseitig aufschaukelnder Circulus vitiosus vorstellbar. In der Tat gibt es Hinweise dafür, dass in den besonders stark von HIV betroffenen Ländern Süd- und Ostafrikas der Anteil der Genitalgeschwüre bei den sexuell übertragbaren Infektionen deutlich höher liegt als in Westafrika (45 bis $46 \%$ bei Männern, 13 bis $68 \%$ bei Frauen vs. $<5 \%$ in Westafrika) [O'Farell et al., TuPeC 3409]. Als Ursache für die Genitalgeschwüre nimmt die Bedeutung der HSV-Infektion z. B. in Durban parallel mit dem Anstieg der HIV-Prävalenz zu. War HSV 1995 noch für 11\% der Genitalgeschwüre bei Männern verantwortlich, so waren es 1998 bereits $45 \%$ [Kharsany et al., ThOrC728]. Problematisch ist diese Entwicklung auch deshalb, weil im Gegensatz zu bakteriellen Geschwürsverursachern (Haemophilus ducreyi, Syphilis) eine antibiotische Therapie nicht möglich ist, bestenfalls eine antivirale Suppressionstherapie, die aber aufgrund der höheren Kosten bislang in Afrika kaum verfügbar ist. 
Neben den "traditionellen" Geschlechtskrankheiten ist auch die sog. bakterielle Vaginose in Afrika sehr viel häufiger (Prävalenz 40 bis 50\%). Ihre Präsenz ist assoziiert mit sexuellem Risikoverhalten, die Besiedlung auch der männlichen Urethra mit denselben Bakterien spricht für eine sexuelle Übertragbarkeit [Bukusi et al., MoOrA229]. Vaginoseassoziierte Mikroorganismen sind auch am Krankheitsbild der Plasmazellendometritis beteiligt, bei dem auch Anaerobier eine Rolle zu spielen scheinen [Nguti et al., MoPeB2237]. Der Beitrag dieses Syndroms zu einer evtl. höheren Infektiosität HIV-Infizierter ist noch unklar.

Ein weiterer lokal wirksam werdender Faktor könnte eine schlechtere Versorgung mit Spurenelementen sein. Eine Untersuchung von Frauen in Mombasa, Kenia, zeigte ein vermehrtes vaginales Shedding von HIV bei Vorliegen einer Seleniumdefizienz. Zu niedrige Seleniumspiegel fanden sich bei $11 \%$ der Studienteilnehmerinnen [Baeten et al., MoOrA226].

Außer den lokalen Einflüssen auf Infektiosität von und Suszeptibilität für eine HIV-Infektion werden auch systemische Einflüsse in die Diskussion gebracht. Wie israelische Wissenschaftler berichteten, die Untersuchungen bei aus Äthiopien stammenden Einwanderern durchführten, sind bei diesen chronische Helmintheninfektionen sehr stark verbreitet. Diese sind mit chronischer Immunstimulierung (Th2-Profil) assoziiert, die zu einer hohen CCR5-Expres-

\section{HIV PREVALENCE BY AGE: WOMAN}

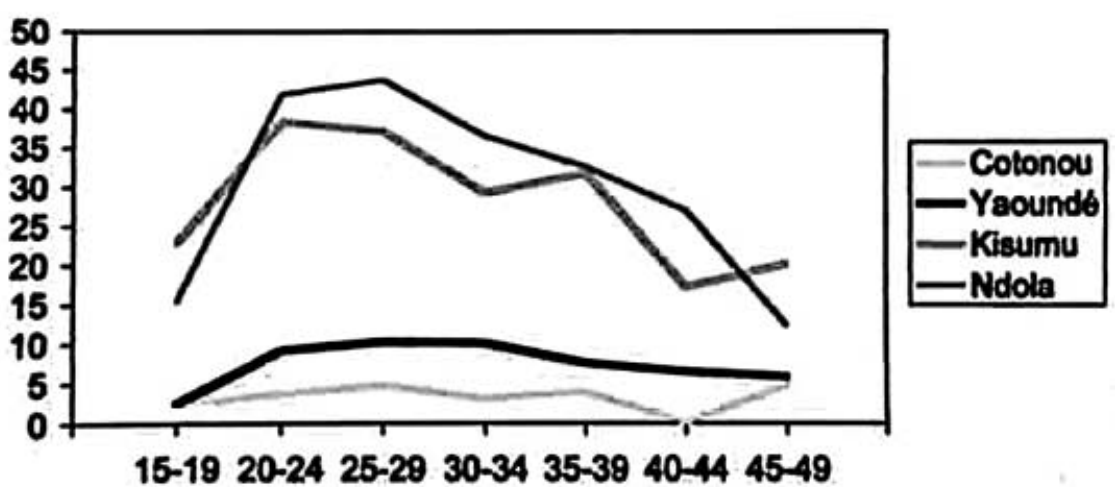

Abb. $18 \Delta$ HIV-Prävalenzen (in \%) in den verschiedenen Altersgruppen bei Frauen in den westafrikanischen Städten Cotonou (Benin) und Yaoundé (Kamerun) sowie in den ostafrikanischen Städten Kisumu (Kenia) und Ndola (Sambia)
Während individuelle Verhaltensparameter (Häufigkeit der Kondomverwendung, Anzahl der Sexualpartner) keine entscheidenden Differenzen zwischen Afrikanern und Europäern oder Amerikanern aufweisen, gibt es doch deutliche Unterschiede bei den von HIV betroffenen Altersgruppen, bei sozialen Faktoren wie dem Ausmaß der Mobilität und - daraus resultierend - bei der Struktur der sexuellen Netzwerke. Diese Unterschiede können ebenfalls zur Erklärung der unterschiedlichen Dynamik der Epidemie herangezogen werden. In den westlichen Industriestaaten erfolgt die überwiegende Zahl der HIVInfektionen in den Altersgruppen der 25- bis 40-Jährigen, in Afrika dagegen, insbesondere in Süd- und Ostafrika, ist die HIV-Inzidenz speziell bei Frauen im Alter zwischen 15 und 25 am höchsten (siehe Abb. 18).

Bei Männern werden hohe HIVPrävalenzen erst in höherem Alter beobachtet, so dass die Mädchen sich kaum beim Sex mit gleichaltrigen oder nur wenig älteren Jungen infizieren können, sondern vorwiegend beim Sex mit älteren, sexuell erfahrenen Männern (siehe Abb. 19). Durch das niedrige Alter bei Infektion gelangt HIV in erheblichem Umfang in die sexuell aktivsten Altersgruppen, die auch die höchste Rate an Partnerwechseln aufweist. Auf die Dynamik der Epidemie dürfte das nicht zu unterschätzende Auswirkungen haben.

\section{"Mobilität ist ein weiterer Faktor, der die Netzwerkstruk- turen beeinflusst."}

Ein weiterer Faktor, welcher die Netzwerkstrukturen beeinflusst, ist die hohe, meist durch Arbeit oder Arbeitssuche bedingte Mobilität. Bei einer Langzeitkohortenstudie in einer ländlichen Region in Uganda wurden beispielsweise 50\% der HIV-Infektionen bei häufig Reisenden beobachtet. Von den Ortsständigeren unterschieden sie sich durch weniger Kondomgebrauch, schlechteren Wissensstand zu HIV und AIDS sowie die Zahl der Sexualpartner [Kintu et al., MoPpC1025]. Die hohe Mobilität begünstigt auch eine hohe Zahl "gleichzeitiger" Partnerschaften, d.h. Männer haben z.B. eine feste Partnerin sowohl an ihrem Heimatort, wie auch an dem Ort, wo sie arbeiten. Beide Partnerinnen werden als 
HIV PREVALENCE BY AGE: MEN

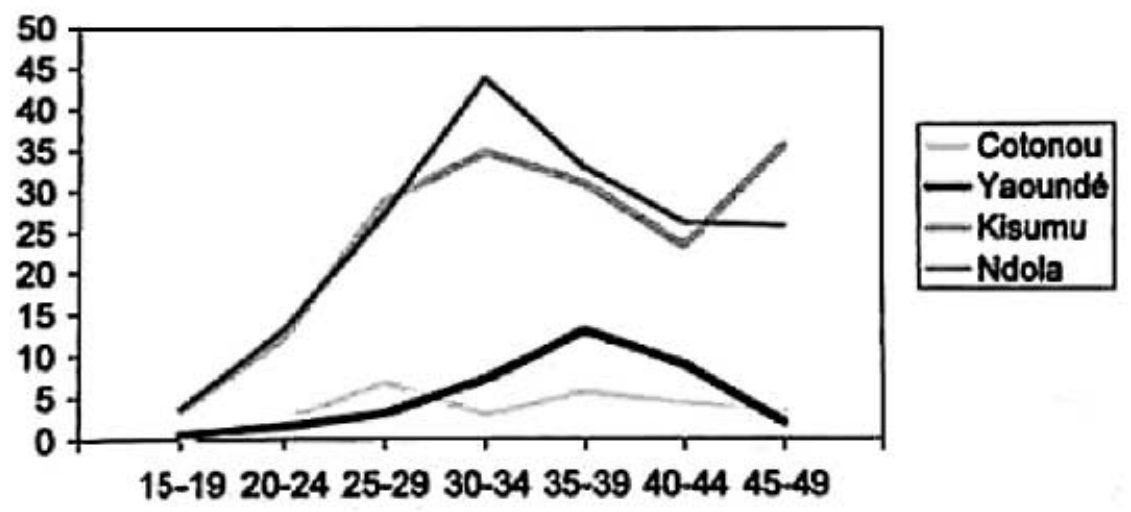

Abb. $19 \Delta$ HIV-Prävalenzen (in \%) in den verschiedenen Altersgruppen bei Männern in den westafrikanischen Städten Cotonou (Benin) und Yaoundé (Kamerun) sowie in den ostafrikanischen Städten Kisumu (Kenia) und Ndola (Sambia)

"feste" Beziehung wahrgenommen. Der Kondomgebrauch in derartigen Partnerschaften ist entsprechend gering. Bei einer Befragung von jungen Erwachsenen (15 bis 29 Jahre) in Kenia berichten $17 \%$ der Frauen und 61\% der Männer über gleichzeitige sexuelle Beziehungen zu mehr als einem Partner im vergangenen Jahr. Von den verheirateten Männern berichtet die Hälfte über mindestens eine weitere Partnerin. Von diesen wiederum bei der Hälfte, also bei insgesamt etwa einem Viertel aller verheirateten Männer, handelte es sich um "Parallelpartnerschaften", die über den gesamten Zeitraum des vorangegangenen Jahres bestanden. Über $80 \%$ der Männer benutzten mit ihrer Ehefrau nie Kondome, mit ihrer zweiten Partnerin waren es über $60 \%$, die auf den Kondomschutz verzichteten [Egesah et al., WePeD4660]. Prinzipiell stellen solche Parallelbeziehungen eine Art Risikominimierungsstrategie dar, welche die Zahl der Partnerschaften begrenzt. Trotzdem wird aber das sexuelle Netzwerk umfangreicher, weil mehr Personen direkt oder indirekt miteinander in Kontakt stehen. Außerdem ist es aufgrund der Beziehungsdynamik in festen Partnerschaften schwieriger, Kondomgebrauch durchzusetzen. Mathematische Modellrechnungen gelangen unter bestimmten Voraussetzungen zu dem Schluss, dass sich das Ausmaß einer HIVEpidemie in einer Population verzehnfacht, wenn die Hälfte der Partnerschaften solche Parallelpartnerschaften sind.

\section{"Afrikanische" Lösungen}

Für einige der Kofaktoren der HIV-Ausbreitung bzw. Hindernisse für eine erfolgreiche Prävention sind innovative Lösungsansätze entwickelt und eingesetzt worden. Zur Verbesserung der STD-Behandlung wurde beispielsweise in Uganda - in Abstimmung mit der nationalen Ärzteorganisation - ein Selbstbehandlungsset zusammengestellt und auf den Markt gebracht. Die Vermarktung wurde begleitet von Aufklärungsund Schulungsmaßnahmen für die Verkaufsstellen, so dass die Verkäufer zusätzlich als Berater und Multiplikatoren fungieren konnten. Das Behandlungsset ist gedacht für Männer, die Ausfluss haben. Es enthält zwei Medikamente, die gegen die häufigsten Erreger von sexuell übertragbaren, Ausfluss verursachenden Infektionen wirksam sind $(1 \times 500 \mathrm{mg}$ Ciprofloxazin, $14 \times 100 \mathrm{mg}$ Doxycyclin). Die Behandlung erfolgt über den Zeitraum einer Woche. In der Packung befinden sich zusätzlich sieben Kondome, drei Karten für Sexualpartnerinnen, mit denen diese sich zu einer Untersuchung vorstellen können, sowie ein mehrsprachiger Beipackzettel [Kambugu et al., ThOrC 765 ]. Als Konsequenz aus der Einführung dieses Behandlungssets stiegen die Heilungsraten von $47 \%$ auf $84 \%$, der Kondomgebrauch während der Behandlung stieg von $18 \%$ auf $36 \%$ (22\% der Käufer benutzten erstmals Kondome), $54 \%$ der Männer unterrichteten ihre Partnerin, und $37 \%$ der Partnerinnen suchte ihrerseits Behandlung.
In einer Reihe von Ländern gibt es mittlerweile "Social marketing"-Kampagnen zur Verbesserung der Verfügbarkeit von Kondomen. Beispielhaft seien kurz die Erfahrungen aus einer ländlichen Region (Masaka) in Uganda geschildert: 1994 gab es in dieser Region Kondome nur in 10\% der Dörfer. Daraufhin wurde eine flächendeckende Verkaufsinfrastruktur etabliert. Die Zahl der verkauften Kondome stieg von 84.000 in 1995 auf 416.000 in 1998 , bei einer Zielpopulation von 90.000 Erwachsenen. Kondome sind in der Region jetzt allgemein verfügbar und gut akzeptiert, Mythen und Fehlinformationen (Kondome vermindern das Vergnügen, Kondome sind mit HIV beschichtet, Kondome sind undicht, Kondombenutzung ist Sünde) sind weitgehend verschwunden. Ein besonderer Aspekt des Social marketing-Programms in Masa$\mathrm{ka}$ ist, dass für die Kondompromotion und -verteilung speziell junge Leute eingespannt wurden, die sich dadurch zusätzlich etwas Geld verdienen konnten und weniger Probleme hatten, mit ihren Altersgenossen über heikle Fragen wie Sexualität $\mathrm{zu}$ reden [Basajja et al., MoOrC244].

Auch die Erfahrungen in anderen Ländern zeigen, dass der Einwand, Kondome seien in Afrika nicht an den Mann $\mathrm{zu}$ bringen, nicht stimmt. So zeigt der Vergleich zweier Repräsentativbefragungen bei Einwohnern Lusakas (Sambia) zu Verhaltensänderungen und Kondomgebrauch aus den Jahren 1996 und 1999, dass der Zugang zu Kondomen von $57 \%$ im Jahre 1996 auf 74\% in 1999 ansteigt. Die Verwendung eines Kondoms beim letzten Geschlechtsverkehr wird 1996 von $17 \%, 1999$ von $21 \%$ der Frauen und von $24 \%$ bzw. $28 \%$ der Männer angegeben. Deutlicher noch geht die Frequenz flüchtiger Sexualpartnerschaften zurück: der Anteil der befragten Frauen, die angeben, ihren letzten Sex mit einem flüchtigen Partner gehabt zu haben, fällt von $7 \%$ auf $3 \%$, bei Männern von $27 \%$ auf $19 \%$. Der Rückgang der Partnerzahlen ist deutlich stärker ausgeprägt bei Wohlhabenderen [Agha, ThPeD5776]. Ein starkes Indiz dafür, dass es sich um reale Verhaltensänderungen und nicht um Untersuchungsartefakte handelt, ist der Rückgang der HIV-Prävalenz bei 15bis 19-jährigen Schwangeren in Lusaka von $28 \%$ in 1993 auf $15 \%$ in 1998. 
Eine Repräsentativbefragung bei knapp 2000 Erwachsenen in Zimbabwe im Jahre 1997 [Adentunji et al., ThPeD5786] ging der Frage nach, welcher Zusammenhang zwischen der Art der Partnerschaft und der Konsistenz des Kondomgebrauches besteht. Ähnlich wie bei der eben geschilderten Untersuchung in Lusaka berichten 20\% der Männer und 6\% der Frauen über flüchtige Sexualpartnerschaften in den vergangenen zwei bis drei Monaten. Von den befragten Männern geben mehr als $80 \%$ an, beim letzten Sex mit einer Prostituierten ein Kondom benutzt zu haben; mehr als 60\% der Männer und Frauen sagen, sie hätten beim letzten Sex mit einem Gelegenheitspartner ein Kondom verwendet; beim letzten Sex mit einem festen Partner (nicht verheiratet) wollen noch immer $60 \%$ der Männer und $40 \%$ der Frauen ein Kondom verwendet haben; beim letzten ehelichen Geschlechtsverkehr lag die Kondomverwendungsrate bei $10 \%$.

\section{"Zahlreiche Kampagnen zeigen, dass Kondome in Afrika durchaus an den Mann zu bringen sind."}

Konsistenten Kondomgebrauch außerhalb von ehelichen Beziehungen geben $53 \%$ der Männer und $37 \%$ der Frauen an, gegenüber $6 \%$ und $8 \%$ mit dem Ehepartner. Auch wenn die Angaben möglicherweise im Sinne einer "sozialen Erwünschtheit” etwas nach oben verfälscht sind, kann man kaum sagen, dass in der "heterosexuellen Allgemeinbevölkerung" in Zimbabwe wesentlich weniger Kondome verwendet werden als in der "heterosexuellen Allgemeinbevölkerung” westeuropäischer Länder. Faktoren, die in der Untersuchung mit höherer Kondomverwendungsrate assoziiert waren, sind eine positive Einstellung gegenüber Kondomen und der Umfang der wahrgenommenen Informationen und Botschaften zum Kondomgebrauch über Medien.
Eine ganze Reihe von Untersuchungen und Analysen gibt ziemlich eindeutige Hinweise darauf, dass der Beschneidungsstatus bei Männern einen einflussreichen Kofaktor für das Risiko eines Mannes darstellt, sich beim heterosexuellen Verkehr mit HIV zu infizieren: beschnittene Männer haben in den entsprechenden Studien ein deutlich geringeres Infektionsrisiko. So erweist sich z. B. beim Vergleich zwischen Yaoundé, Kamerun (3,8\% HIV-Prävalenz) und Cotonou, Benin $(4,4 \%)$, mit Kisumu, Kenia $(21,9 \%)$ und Ndola, Sambia (25,9\%) der Beschneidungsstatus als starker protektiver Faktor (>99\% beschnitten vs. 26,8\% bzw. 7,6\%) [Buve et al., MoOrC192].

\section{"Die präpubertäre Beschneidung bei Männern senkt das Risiko, sich beim heterosexuellen Verkehr zu infizieren."}

Die epidemiologischen Hinweise und die biologische Plausibilität (geringere Schleimhautkontaktfläche), die für den protektiven Effekt der Beschneidung sprechen, geben Anlass, über Beschneidung als ein Element der HIV-Präventionsstrategie nachzudenken. Eine Befragung beim Volksstamm der Luo in Kenia ergab, dass die Akzeptanz einer solchen Maßnahme dort sehr hoch wäre: $60 \%$ der Männer würden sich beschneiden lassen, und $62 \%$ der Frauen würden beschnittene Partner bevorzugen. Allerdings haben die lokalen Ärzte und das Gesundheitspersonal keine Erfahrung mit der Beschneidung und Instrumente und Know-how fehlen [Bailey et al., MoOrC196]. Eine Analyse der Beschneidungssitten bei verschiedenen Volksstämmen in Südafrika ergibt eine erhebliche Variationsbreite hinsichtlich des Alters bei der Beschneidung [Taljaard et al., MoOrC195]. Die Frage, in welchem Alter eine Beschneidung vorgenommen wird, könnte durchaus praktische Bedeutung haben: eine retrospektive Auswertung des Zusammenhanges zwischen HIV-Risiko und Zeitpunkt der Beschneidung in der Rakai-Studie in Uganda gelangt zu dem Ergebnis, dass zwar die präpubertale Beschneidung statistisch einen protektiven Effekt hat, die postpubertale hingegen nicht [Gray et al., MoOrC193].

\section{Der natürliche Verlauf der HIV- Infektion in Afrika}

Es wurde häufig vermutet, dass der natürliche Verlauf der HIV-Infektion in Entwicklungsländern schneller sei als in den Industriestaaten, da Kofaktoren wie andere Begleitinfektionen, Mangelernährung etc. in Entwicklungsländern häufiger seien. Eine Langzeitkohortenstudie aus Uganda liefert nunmehr erstmals harte Zahlen zu dieser Frage. Die in einer ländlichen Region 1990 begonnene Studie hat 107 bereits vor 1990 Infizierte, 153 nach Aufnahme in die Studie Infizierte und $240 \mathrm{HIV}$-negative Kontrollpersonen seitdem in dreimonatlichen Abständen untersucht. Zur Behandlung von Erkrankungen standen Medikamente der WHO Essential Drug List (keine antiretrovirale Therapie) zur Verfügung. Fünf Jahre nach Serokonversion waren $17 \%$ der HIV-Infizierten verstorben, neun Jahre nach Serokonversion $35 \%$. Bei den seropositiven Teilnehmern waren $80 \%$ der Todesfälle auf AIDS zurückzuführen. Die durchschnittliche Überlebensdauer nach der ersten AIDS-definierenden Erkrankung lag bei knapp elf Monaten. Die häufigsten AIDS-definierenden Erkrankungen waren Wasting Syndrom, Candidiasis des Ösophagus und langdauernde ausgedehnte Herpes simplex Manifestationen [Morgan et al., TuOrC428]. Zumindest unter regelmäßiger ärztlicher Kontrolle und bei Verfügbarkeit einiger wesentlicher Medikamente zur Behandlung von opportunistischen Erregern scheint der natürliche Verlauf der HIV-Erkrankung in Afrika demnach nicht schneller zu sein als in den Industrieländern vor Einsatz der hochaktiven Kombinationstherapien. Diese Studie bringt einige Theorien zu infektiösen oder ernährungsbedingten Kofaktoren der HIV-Krankheitsentwicklung ins Wanken. 
Als häufigste Erkrankungen wurden in einer klinischen Kohortenstudie bei HIV-Infizierten in Uganda Pneumonien, Tuberkulose, Herpes zoster, systemische Pneumokokkeninfektionen und Malariaepisoden registriert. Die Ursache von ca. einem Drittel der Fieberepisoden war mit den verfügbaren Untersuchungsmöglichkeiten nicht diagnostizierbar. Die Erstvorstellung in der Klinik erfolgte bei relativ niedrigen $\mathrm{CD}_{4}$ Zellzahlen (Median 224 CD4-Zellen/ $\mu$ l) und einem Durchschnittsalter von 30 Jahren [Nakiyingi et al., MoPeB2304]. Bei einer retrospektiven Analyse der klinischen Manifestationen, mit denen in Nigeria Personen mit bekanntem positivem HIV-Status in Gesundheitseinrichtungen behandelt wurden, wurden folgende Erkrankungen in absteigender Reihenfolge am häufigsten diagnostiziert: Tuberkulose (38\%), Candidiasis (26\%), Hautinfektionen (21\%), Herpes zoster (18\%) und das Kaposisarkom (10\%). Medikamente zur Behandlung der Infektionen sind in den Kliniken oft nicht vorhanden [Idigbe et al., TuPeB3133].

Angesichts der Bedeutung der Tuberkulose und anderer Atemwegsinfektionen für die Morbidität bei HIV-Infizierten und in Anbetracht der Nichtverfügbarkeit antiretroviraler Therapien drängt sich die Frage auf, ob nicht durch Primärprophylaxen und/oder Impfungen wie die Pneumokokkenimpfung bestimmte Erkrankungen verhindert und so die klinische Manifestation eines Immundefektes hinausgezögert werden könnte. Häufige Erreger der bei HIV-Infizierten sowohl in Afrika wie auch in den Industriestaaten auftretenden bakteriellen Pneumonien sind Pneumokokken. Zur Prävention von Pneumokokken-Infektionen gibt es PolysaccharidImpfstoffe. Seit mehreren Jahren gibt es in einigen Industriestaaten wie den USA und Großbritannien Empfehlungen, diesen Impfstoff bei HIV-Infizierten einzusetzen. Diese Empfehlungen sind aber nicht durch Wirksamkeitsstudien bei HIV-Infizierten untermauert. In vielen Ländern, u. a. auch in Deutschland, besteht nicht zuletzt deshalb auch kein Konsens über den Einsatz dieses Impfstoffes bei HIV-Infizierten. Diese Zurückhaltung scheint sich als nicht ganz unbegründet zu erweisen, nachdem eine plazebokontrollierte Doppelblindstudie mit fast 1400 erwachsenen HIV-infizier- ten Teilnehmern in Uganda zu dem Ergebnis gelangt, dass der Impfstoff in dieser Population keine Wirksamkeit zeigt [9]. Die Gründe für das Ausbleiben der erwünschten Wirkung sind noch nicht völlig geklärt. Eine kleine Studie bei HIV-infizierten Kindern in Griechenland, bei der quantitative und qualitative Antikörpermessungen vorgenommen wurden, zeigt, dass die Antikörperkonzentration durch die Impfung nicht erhöht wird und die Antikörper-Avidität sogar abnimmt [10]. Die Datenlage zur medikamentösen Primärprophylaxe ist widersprüchlich. Eine Prophylaxestudie mit Gabe von Isoniazid und Cotrimoxazol in Westafrika führte zu einer verringerten Morbidität und Mortalität [11].

\section{"Der mit dem wesentlichen natürliche Verlauf der HIV- Erkrankung in Afrika scheint nicht schneller zu sein als in den Industrieländern vor Einsatz der hochaktiven Kombinationstherapien."}

Bei HIV-positiven Bergleuten in Südafrika wurde ebenfalls eine kombinierte $\mathrm{Tb}$ - und Pneumonie-Prophylaxestudie mit Isoniazid und Cotrimoxazol durchgeführt. Der Krankheitsverlauf bei den Teilnehmern in der Studienkohorte wurde verglichen mit dem Verlauf in einer Beobachtungskohorte ohne medikamentöse Prophylaxe. In der Studienkohorte wurden zwar weniger Krankenhauseinweisungen und weniger Tuberkuloseerkrankungen registriert, aber die Gesamtmortalität und die Inzidenz von Pneumonien war unerwarteter Weise höher als in der Beobachtungskohorte. Eine denkbare Erklärung für diese Unterschiede könnte sein, dass die HIV-Infizierten in den verglichenen Kohorten sich möglicherweise in unterschiedlichen Erkrankungsstadien befanden. Andererseits kann sich aber auch das Spektrum der Infektionserreger in Südafrika so sehr von dem in Westafrika unterscheiden, dass Cotrimoxazol vielleicht nicht das ideale Prophylaxemedikament in dieser Population darstellt. Die Schlussfolgerung der Studienleiter lautet, randomisierte Vergleichsstudien mit Cotrimoxazol vs. Plazebo oder vs. andere Antibiotika seien notwendig [Churchyard et al., TuPeC3383]. Ein zu- mindest theoretischer Vorteil von Cotrimoxazol ist, dass dieses Antibiotikum Wirksamkeit u. a. auch gegen Haemophilus influenzae, Salmonellen, Toxoplasma und einige Staphylokokkenvarianten entfaltet, allerdings begünstigt es die Manifestation einer Candidiasis [Dworkin et al., TuPeB3137].

Die unbefriedigende Datenlage hinsichtlich der Wirksamkeit von Primärprophylaxen gegen häufige opportunistische Erkrankungen in Afrika bleibt aber solange ein nachrangiges Problem, als in den meisten Ländern - sei es aus finanziellen Gründen, sei es wegen der mangelhaften Infrastruktur - noch nicht einmal die Medikamente für die Behandlung akuter Komplikationen zur Verfügung stehen. Selbst eine palliative Behandlung (u.a. Schmerzmedikamente, symptomatische Therapie von Durchfällen), deren Kosten in Afrika bei ca. 20 US \$/Patient/Jahr liegen, bleibt für viele HIV/AIDS-Patienten unerreichbar. Nach Berechnungen der Weltbank betragen die Kosten für eine palliative Behandlung plus Behandlung "billiger" opportunistischer Infektionen (Tuberkulose, PcP, Toxoplasmose, Candidiasis, Pneumonie/Sepsis) in Afrika etwa 300 US \$/Patient/Jahr, in Thailand etwa 1000 US \$. Berücksichtigt man die Kosten für palliative Behandlung plus Behandlung aller opportunistischer Infektionen liegen die Kosten in Afrika bei 500 US \$, in Thailand bei 1650 US \$ pro Patient und Jahr (Quelle: Weltbank, Confronting AIDS). Eine andere Rechnung machen Maniar et al. aus Bombay, Indien, auf [Maniar et al., TuPeB3142]. Nach ihren Berechnungen betragen die Kosten für die Behandlung opportunistischer Infektionen bei einem AIDS-Patienten in Bombay ca. 10.00o US \$/Jahr. Dies beinhaltet eine Behandlung für Tuberkulose, Candidiasis, PcP, Toxoplasmose, Kryptokokkenmeningitis, rezidivierenden Herpes simplex, CMV-Retinitis, Sepsis und Diarrhoe). Demgegenüber betragen die Kosten für eine antiretrovirale Dreifachkombinationstherapie, die in Indien teilweise mit billigen Generika anstelle von teuren, patentgeschützten Originalmedikamenten erfolgen kann, einschließlich der notwendigen Laboruntersuchungen, ca. 5000 US \$/Jahr. In den entwickelten Industriestaaten betragen die Medikamentenkosten für eine HAART derzeit etwa 10.000 bis 15.000 US \$ pro Jahr. 
Die Preise für antiretrovirale und andere in der AIDS-Behandlung unverzichtbare patentgeschützte Medikamente könnten nach Angaben der Organisation "Mediziner ohne Grenzen" für ärmere Länder - sei es durch freiwillige Preisnachlässe durch die Herstellerfirmen, sei es durch Duldung und Ermöglichung von Preiskonkurrenz durch Generika - auf 5 bis 10\% der derzeitigen Marktpreise gesenkt werden. Es gibt keinen rationalen Grund, der gegen ein zweigeteiltes Preissystem für lebenswichtige Medikamente spricht. Solange den Pharmafirmen gestattet wird, über den Patentschutz für ihre Medikamente in ihrem Hauptmarktsegment, den entwickelten Industriestaaten, die Forschungs- und Entwicklungskosten zu finanzieren, haben sie von der Abgabe der Medikamente $\mathrm{zu}$ einem geringfügig über den Herstellungskosten liegenden Preis in einem Marktsegment, welches ansonsten gar nicht vorhanden wäre, keine finanziellen Nachteile zu befürchten. Dem Risiko eines Schwarzmarktes mit illegalen Re-Importen kann mit Kontrollmaßnahmen begegnet werden, so dass dieses Argument gegenüber den Behandlungsinteressen von Millionen bisher von der Therapie ausgeschlossenen Patienten zurücktreten muss. Natürlich kann in Afrika nicht von heute auf morgen flächendeckend antiretrovirale Kombinationstherapie eingesetzt werden. Aber wenn ernsthaft am Aufbau einer menschenwürdigen medizinischen Betreuung und Versorgung gearbeitet wird, könnte es letztlich keinen großen finanziellen Unterschied mehr machen, ob eine Therapie für opportunistische Infektionen durchgeführt wird oder eine antiretrovirale Kombinationstherapie.

\section{Was muss getan werden?}

AIDS ist in Afrika längst kein reines $\mathrm{Ge}$ sundheitsproblem mehr, sondern das größte Hindernis für die weitere wirtschaftliche und gesellschaftliche Entwicklung und eine Bedrohung für die soziale und politische Stabilität des ganzen Kontinents. Die bisherigen Anstrengungen zur Prävention und zur Bewältigung des Problems haben sich als weitestgehend unzureichend erwiesen. $\mathrm{Zu}$ den wenigen Ausnahmen zählen der Senegal, wo die HIV-Prävalenz auf einem vergleichsweise sehr niedrigen Niveau $(<1 \%$ in der Allgemeinbevölkerung) gehalten werden konnte und Uganda, welches Mitte der achtziger Jahre eine der höchsten Prävalenzraten in Afrika aufwies und welches es ge-

\section{Prevalence of sexually transmitted diseases among sex workers, Dakar, Senegal, 1991 and 1996}

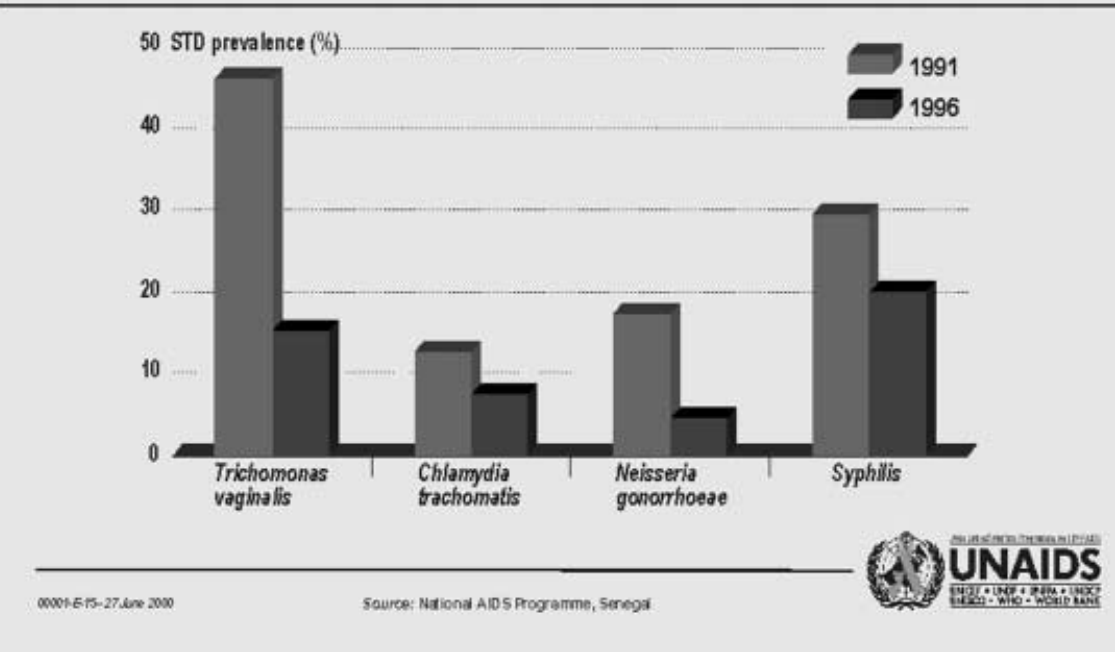

Abb. $20 \Delta$ Bei niedriger HIV-Prävalenz in der Gesamtbevölkerung sind Programme zur Prävention von HIV und anderen Geschlechtskrankheiten in besonderen Risikopopulationen, wie z. B. bei Prostituierten, besonders wirkungsvoll. Die Grafik zeigt den Erfolg einer verbesserten STD-Behandlung und -prophylaxe bei Prostituierten in Dakar, Senegal (Quelle: Nationales AIDS-Programm, Senegal)

schafft hat, die Prävalenzraten vor allem bei jungen Menschen deutlich zu reduzieren. Beide Länder zeichnen sich durch eine hohe Bereitschaft der politischen Führung aus, das Problem AIDS offen zu diskutieren, mit Betroffenen in der Prävention und bei der Betreuung zusammenzuarbeiten, in der Prävention pragmatische Lösungen zu suchen und Diskriminierung und Stigmatisierung von AIDS-Kranken abzubauen (Abb. 20, 21).

Demgegenüber haben die Regierungen in den meisten betroffenen Ländern das Problem zunächst totgeschwiegen, politisch zum Teil mit diskriminierenden Intentionen instrumentalisiert, mit populistischen Parolen und Maßnahmen die Stigmatisierung von Betroffenen eher verstärkt als abgebaut. Eine typische und immer wiederkehrende Reaktion von Regierungen (weltweit und keineswegs nur in Afrika) auf die Gefahr einer AIDS-Epidemie ist, dass das Problem zunächst mit der Begründung verleugnet wird, dass es sexuelles Risikoverhalten wie außerehelichen Sex, Prostitution, intravenösen Drogenmissbrauch und Homosexualität in dem betreffenden Land nicht in relevantem Ausmaß gibt. Diese Vogel-Strauß-Politik hat regelmäßig zur Konsequenz, dass eine frühzeitige und wirksame Prävention verzögert wird und die Epidemie sich zunächst ungehindert ausbreiten kann. Ein Teil des Problems besteht also aus mangelnden Führungsqualitäten. Zumindest auf der Ebene verbaler $\mathrm{Ab}$ sichtserklärungen zeichnet sich hier jedoch ein deutlicher Wandel ab. Mehr und mehr wird das Problem auch von den politischen Führungseliten ernst genommen und öffentlich zur Sprache gebracht. Dieser Prozess könnte durch stärkeren innenpolitischen Druck, durch eine Mobilisierung der Betroffenen, beschleunigt werden. Dies setzt eine Überwindung der Problemverleugnung, Hoffnungslosigkeit und Apathie voraus. Es handelt sich also nicht nur um ein politisches, sondern auch um ein gesellschaftlich-psychologisches Problem. Eine derartige Mobilisierung wird sich am ehesten rund um die Problematik einer menschenwürdigen Behandlung und Versorgung entwickeln. Die bisherigen Erfahrungen zeigen, dass Engagement und Selbstorganisation von Betroffenen zu einem offeneren und vorurteilsfreieren Klima in der Gesellschaft 


\section{Median HIV prevalence among pregnant women in urban areas in Uganda, 1985 to 1998}

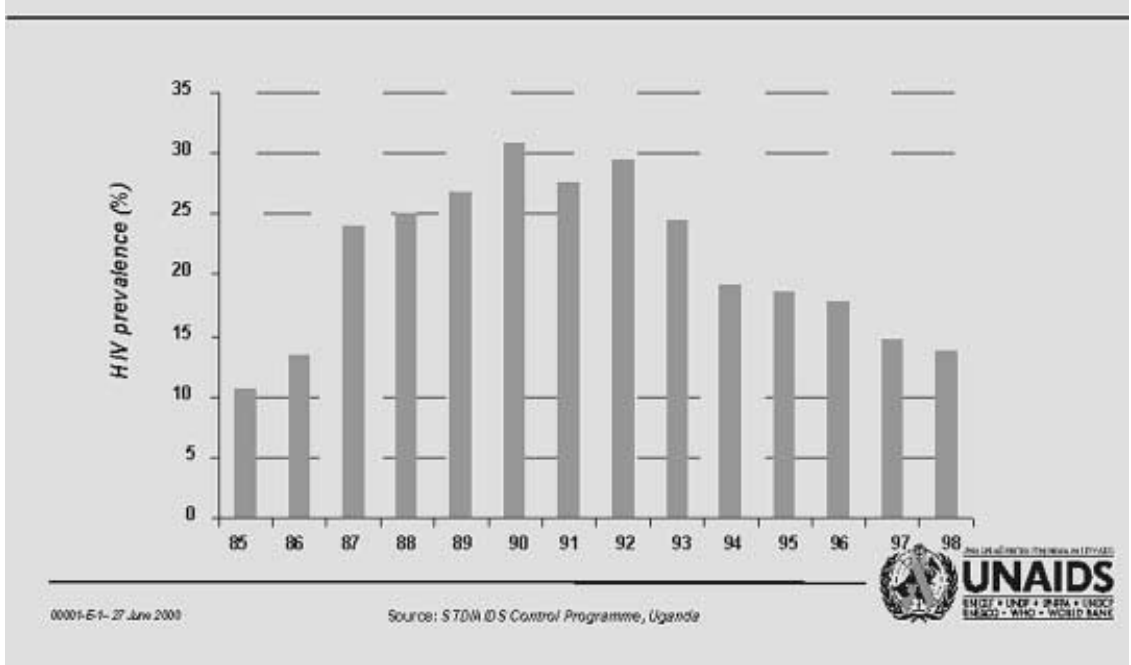

Abb. $21 \Delta$ Uganda ist bislang das einzige Land in Afrika, in dem es gelungen ist, durch eine kontinuierliche, koordinierte, von der politischen Führung entschieden unterstützte Präventionspolitik eine sehr hohe HIV-Prävalenz deutlich zu senken: der Rückgang der Neuinfektionsraten beruht auf deutlich gestiegenem Kondomgebrauch, einer Verminderung der durchschnittlichen Zahl der Sexualpartner und einem Hinauszögern der Aufnahme sexueller Beziehungen bei Jugendlichen. Nicht von ungefähr herrscht eine relativ große Offenheit im Umgang mit dem Thema AIDS, und Antidiskriminierungs- und Antistigmatisierungsbotschaften sind wesentliche Bestandteile der AIDS-Politik in Uganda

beitragen und damit auch die Effektivität von Präventionsmaßnahmen positiv beeinflussen. Prävention und menschenwürdige Behandlung von Infizierten und Erkrankten dürfen daher nicht als konkurrierende Notwendigkeiten begriffen werden, sondern beides sind unverzichtbare Bestandteile einer Gesamtstrategie.

\section{"Die Vogel-Strauß-Politik der Regierungen führt dazu, dass eine frühzeitige und wirksame Prävention verzögert wird und die Epidemie sich zunächst un- gehindert ausbreiten kann."}

Problematisch ist aber zweifellos die Prioritätensetzung bei extrem begrenzten Ressourcen. Bei einer ausgeprägten Epidemie wie in den meisten Ländern Schwarzafrikas wird der Druck der öffentlichen Meinung zunächst in Richtung besserer Behandlung, Verhinderung der Mutter-Kind-Übertragung und Sicherung der Blutversorgung zielen. Gezielte Präventionsmaßnahmen für marginalisierte Gruppen wie Prostitu- ierte, Personen mit häufig wechselnden Partnern und STD-Patienten, wenngleich sehr effektiv was die Verlangsamung der HIV-Epidemie angeht, werden nur geringe Unterstützung in der Öffentlichkeit erfahren. Guter Wille und Engagement allein reichen daher nicht, wenn die materielle und personelle Basis fehlt. Präventionskampagnen und Kondome kosten Geld, Krankenhäuser, ambulante Versorgungseinrichtungen und häusliche Krankenpflege auch. Vieles, aber nicht alles, kann durch freiwilliges Engagement geleistet werden, zumal in Gesellschaften, in denen ein erheblicher Teil der Menschen in Armut lebt und seine Energie darauf konzentrieren muss, die Mittel zum Lebensunterhalt für den nächsten Tag oder die nächste Woche aufzutreiben. UNAIDS hat versucht zu errechnen, was an finanziellen Aufwendungen erforderlich ist, um eine Trendwende in der HIV-Epidemie in Afrika zu erreichen. Auf der Grundlage erfolgreicher Programme wurde berechnet, was notwendig wäre, um flächendeckend AIDS-Aufklärungsprogramme für die Allgemeinbevölkerung, Sexualerziehung und AIDS-Aufklärung in den Schulen, Programme zur besseren Erkennung und Behandlung von Geschlechtskrankheiten, eine Verbesserung der medizinischen Versorgung (Prophylaxe, Diagnose und Behandlung leicht therapierbarer opportunistischer Infektionen, palliative Behandlung bei Schmerzen und Durchfällen) und Krankenbetreuung (Hauskrankenpflege), Aufbau einer Infrastruktur von Test- und Beratungseinrichtungen, Schulung und Ausbildung entsprechenden Personals zu finanzieren. Die als eher konservativ einzuschätzende Berechnung gelangt auf einen Betrag von 3 Mrd. US \$ pro Jahr - die gesamte internationale Hilfe aus Geberländern für AIDS-Aktivitäten betrug 1998 nur 300 Mio. US $\$$. Auch wenn die betroffenen Länder z. T. selbst noch neue Ressourcen durch Umschichtungen mobilisieren könnten und durch einen Schuldenerlass weitere Mittel für diesen Bereich verfügbar werden könnten, ist ein solcher Betrag nur durch eine erhebliche Steigerung der Hilfe aus den reichen Industrienationen aufzubringen. Zumal auch die Wirtschaftskraft der am stärksten betroffenen Regionen durch die Auswirkungen der Epidemie zurückgeht und Staatseinnahmen und viele Familieneinkommen in den kommenden Jahren deutlich sinken werden.

Es gibt erste Signale in die richtige Richtung: die Weltbank kündigte vor kurzem ein neues AIDS-Programm in einer Größenordnung von 500 Mio. US $\$$ an. Japan kündigte ein Programm zur Bekämpfung von AIDS, Malaria und Tuberkulose in Entwicklungsländern an, für das über einen Zeitraum von mehreren Jahren insgesamt 3 Mrd. US \$ zur Verfügung gestellt werden sollen. Auch die EU kündigt neue Programme an, hat sich über die Größenordnung aber noch nicht geäußert. Die USA haben für das Jahr 2000 zusätzliche Finanzmittel in Höhe von 65 Mio. US \$ und für 2001 weitere 100 Mio. zugesagt. Einzelne Pharmafirmen wie Bristol Myers Squibb engagieren sich mit Projekten wie dem "Secure the future"-Programm, mit dem Länder in Südafrika über einen Zeitraum von fünf Jahren 100 Mio. US \$ in den Bereichen medizinische Forschung, Aus- und Weiterbildung, Organisation von Hauskrankenpflege, Versorgung von Waisen etc. unterstützt werden. Stiftungen wie die Bill und Melinda Gates Stiftung engagieren sich ebenfalls mit mehrstelligen Millionenbeträgen. Die bisherigen Zusagen sind aber noch weit 
von dem erforderlichen Betrag entfernt, und man muss sich darüber im Klaren sein, dass längerfristiges Engagement notwendig sein wird (Abb. 22).

\section{Was kann Deutschland tun?}

Deutschland hat auf dem G8-Gipfeltreffen in Okinawa zusammen mit den anderen Teilnehmerstaaten versprochen, bis zum Jahre 2010 die Zahl der jungen Menschen, die mit HIV infiziert sind, um $25 \%$ zu senken, die Zahl der Tuberkulose- und Malariaopfer zu halbieren. Wenn diese Versprechungen keine wohlfeilen Lippenbekenntnisse bleiben sollen, müssen zunächst einmal die im Entwicklungshilfeetat zur AIDS-Bekämpfung und zum Infrastrukturaufbau zur Verfügung gestellten Mittel drastisch erhöht werden. Auf der internationalen Ebene kann Deutschland seinen Einfluss in Institutionen wie der Weltbank und der Europäischen Union geltend machen, um deren AIDS-Programme auszubauen. Deutschland sollte dem Beispiel anderer Länder (z. B. Niederlande, Großbritannien) folgen und wichtige internationale Initiativen wie IAVI (Internationale AIDS Vaccine Initiative) finanziell unterstützen. Die Diskussionen vor der Welt-AIDS-Konferenz und auf der Konferenz selbst haben gezeigt, dass es durchaus gangbare Wege gibt, Medikamente zur Therapie von opportunistischen Infektionen und von HIV für Entwicklungsländer erheblich $\mathrm{zu}$ verbilligen und dadurch überhaupt erst verfügbar zu machen. Hier könnten einfache und klare politische Stellungnahmen helfen. Die EU sollte, wie die USA dies bereits getan haben, erklären, dass kein wirtschaftlicher oder politischer Druck auf Entwicklungsländer ausgeübt wird, die die vorhandenen rechtlichen Möglichkeiten internationaler Handelsund Patentschutzvereinbarungen dazu nutzen, generische Versionen patentierter Medikamente selbst zu produzieren oder zu importieren. Um die Herstellerfirmen von AIDS-Medikamenten $\mathrm{zu}$ ermuntern, selbst ebenfalls deutliche Preisnachlässe für arme Länder zu gewähren, sollten die reichen Industriestaaten erklären, dass ein zweigeteiltes Preissystem für derartige Medikamente akzeptiert wird: hohe Preise in reichen Ländern, die es den Herstellerfirmen erlauben, ihre Forschungs- und Entwicklungskosten $\mathrm{zu}$ bestreiten und niedrige Preise in der Höhe der reinen Herstellungs- und Vertriebskosten in den armen Ländern. Die Akzeptanz eines zweigeteilten Preissystems darf aller-

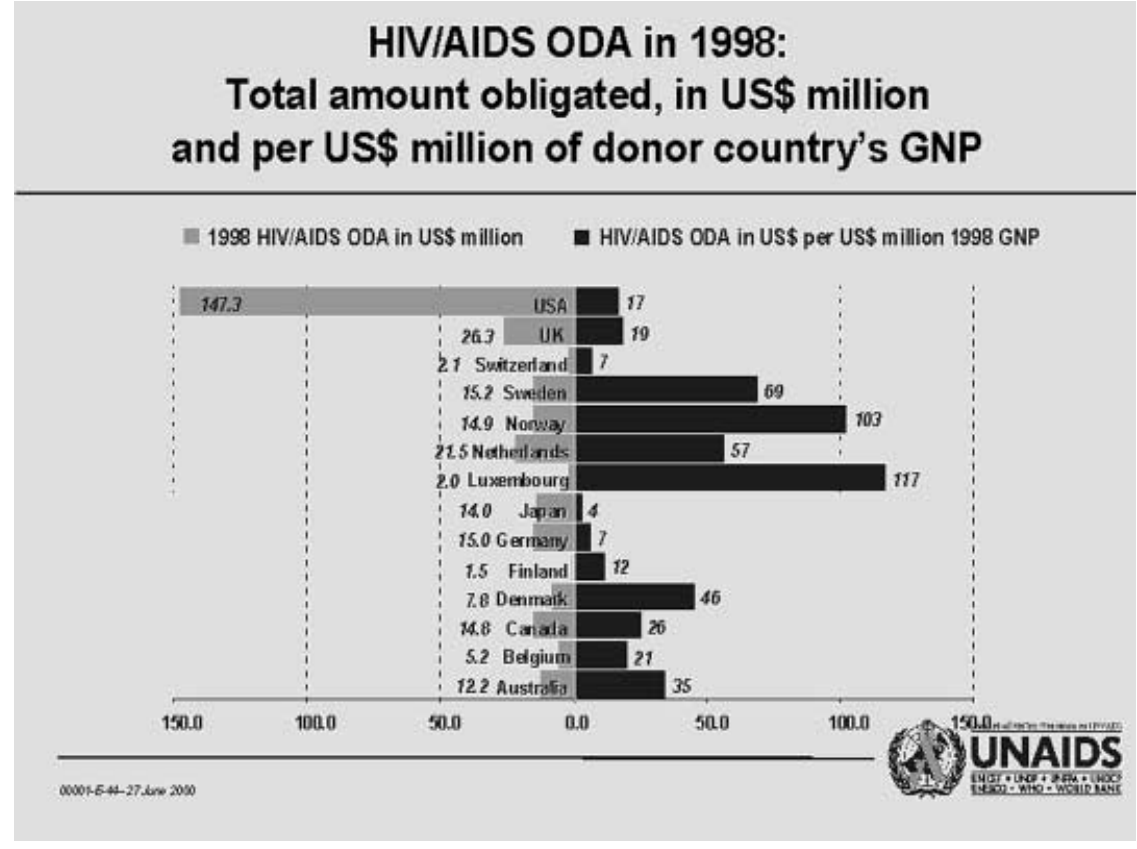

Abb. $22 \triangle$ Finanzhilfen für HIV/AIDS-bezogene Projekte in Entwicklungsländern im Jahre 1998: die Balken links geben die absolute Höhe der Hilfen in Mio. US \$ an, die Balken rechts geben das Verhältnis der Hilfsleistungen zur Höhe des Bruttosozialproduktes an. Nach beiden Berechnungsgrundlagen steht der deutsche Beitrag in keinem Verhältnis zur wirtschaftlichen Bedeutung Deutschlands (Quelle: UNAIDS) dings nicht zu einem Freibrief für ungerechtfertigte Wucherpreise in den Industriestaaten werden.

Auf nationaler Ebene gibt es weitere Bereiche, in denen konkrete und hilfreiche Schritte möglich sind, darunter auch einige eher symbolische Akte, die nichtsdestoweniger eine wichtige psychologische Funktion haben könnten:

D Abbau diskriminierender Bestimmungen im AIDS-Bereich, die sich besonders im Bereich der Ausländerpolitik gehalten haben. Dazu gehören Zwangstestung von Asylbewerbern und Auslandsstipendiaten. Stattdessen sollten Aufklärungs- und Versorgungsangebote besser auf die Bedürfnisse ausländischer Mitbürger ausgerichtet werden. Dazu gehört auch eine offizielle Erklärung, dass ein positiver HIV-Status so lange als humanitäres Abschiebehindernis anerkannt wird, als in den Herkunftsländern vergleichbare und angemessene Therapiemöglichkeiten nicht zur Verfügung stehen.

D Angesichts der Tatsache, dass die stark von AIDS betroffenen Länder die Aufwendungen zur Ausbildung von qualifiziertem Fachpersonal erhöhen müssen, um die krankheitsbedingten Ausfälle zu kompensieren, sollten auch die Ausbildungskontingente für Auslandsstipendiaten aus diesen Regionen in Deutschland erhöht werden.

D Angebote zur Zusammenarbeit bei Prävention und Infrastrukturentwicklung inklusive eines Know-howTransfers. Dabei sollte nur dort, wo unbedingt notwendig, die Entsendung von Personal erfolgen. Ausländische Experten, die in teuren Hotels oder Villen mit Swimmingpool leben, diskreditieren die Glaubwürdigkeit ausländischer Hilfsangebote. In bestimmten Bereichen wie bei qualifiziertem medizinischen Personal, welches in vielen betroffenen Ländern fehlt und auch nicht kurzfristig ausgebildet werden kann, kann aber auch personelle Unterstützung hilfreich sein. In Entwicklungsländern selbst ausgebildetes medizinisches Personal wandert oft in reichere Länder $\mathrm{ab}$ und steht für die medizinische Versorgung damit nicht mehr zur Verfügung. Von 600 in Sambia seit Beginn der Unabhängigkeit ausgebildeten Ärzten arbeiten z. B. nur 
noch 50 im staatlichen Gesundheitswesen des Landes.

D Nützliches Know-how hätte Deutschland beispielsweise hinsichtlich der Entwicklung und Durchführung von Präventionskampagnen anzubieten (Werbung für Kondome, gesellschaftliche Solidarität mit Infizierten, Abbau von Diskriminierung), sowohl was massenmediale als auch was zielgruppenspezifische Kampagnen betrifft, und die Zusammenarbeit von staatlichen und Selbsthilfeorganisationen ist in weiten Bereichen durchaus beispielhaft.

Im Bereich der sozialwissenschaftlichen Forschung können Projekte zur Verbesserung der Prävention für Migranten und zur Identifizierung und Überwindung von Zugangsbarrieren zum medizinischen Versorgungssystem wertvolle Erkenntnisse gewinnen, die auch für Entwicklungsländer interessant werden könnten. Darüber hinaus wäre Knowhow-Transfer und Zusammenarbeit hinsichtlich Evaluations- und Implementierungsforschung denkbar. Im medizinischen Bereich könnte eine Zusammenarbeit bei medizinischen Therapiestudien zur Entwicklung einfacherer und bil- ligerer Therapieformen erfolgen, eine Zusammenarbeit z. B. bei der Erforschung der Mutter-Kind-Übertragung könnte sehr fruchtbar sein. Deutschland hatte in diesem Bereich - international leider nicht gebührend gewürdigte - Erfolge erzielt und Spitzenforschung betrieben. Es kann nur als Skandal bezeichnet werden, dass die Forschungsaktivitäten in diesem Bereich dem Rotstift zum Opfer fallen und quasi abgewickelt werden. Ein weiterer Bereich, in dem Deutschland mehr Aktivität entfalten könnte, ist die Entwicklung billiger und unaufwendiger Diagnostika z. B. zur Diagnose von STDs, opportunistischer Infektionen und zur Therapieverlaufskontrolle. Schließlich sollte man sich Gedanken darüber machen, wie neben öffentlichen Mitteln auch die private Hilfsbereitschaft stimuliert werden kann. Obwohl z. B. im Zusammenhang mit Naturkatastrophen die Deutschen durchaus eine hohe Spendenbereitschaft zeigen, gab es bislang kaum Versuche in Deutschland, für AIDS-Projekte oder AIDS-Prävention in Entwicklungsländern Spenden zu sammeln. Eine Herausforderung dabei ist sicherlich, dass es eines kontinuierlichen Engagements über viele Jahre hinweg bedarf.

\section{Vorausblick auf Teil 2}

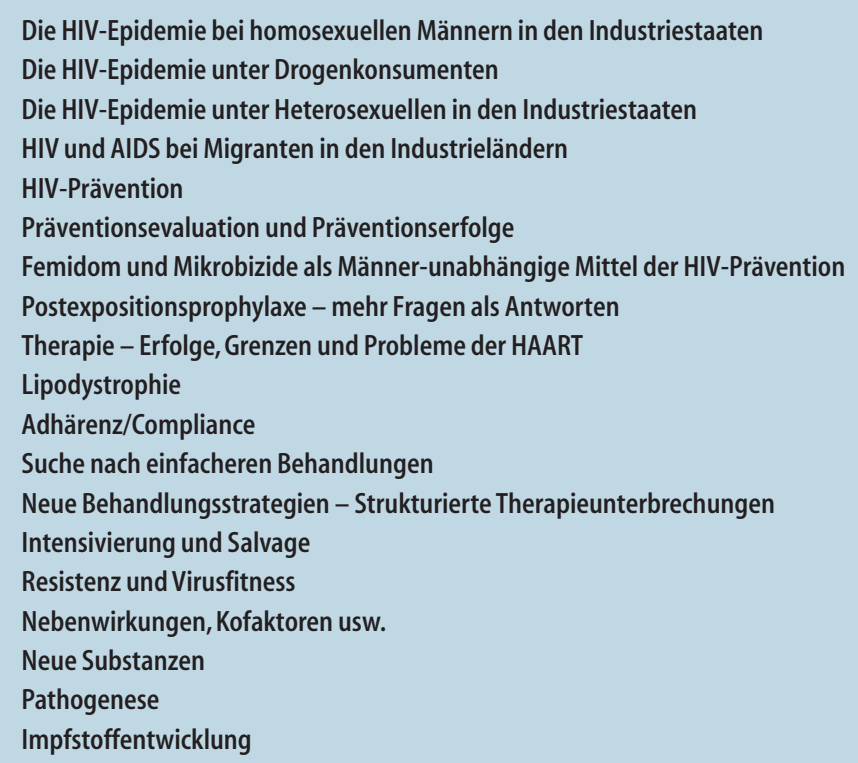

\section{Literatur}

Die Titel und Ko-Autoren der in Klammern aufgeführten Konferenzabstracts können auf den Internetseiten der Konferenz http://www.aids2000.com (klicken auf itinerary builder) recherchiert werden.

1. Mudur $\mathrm{G}(2000)$ Indian agency admits publishing "wrong" HIV figures. BMJ 321:402

2. Normile D (2000) China awakens to figth projected AIDS crisis. Science 288:2312

3. Sweat $M$, Gregorisch S, Sangiwa G, Furtonge $C$, Balmer D, Kamenga C, Grinstead, 0, Coates T (2000) Cost-effectivness of voluntary HIV-1 counselling and testing in reducing sexual transmission of HIV-1 in Kenya and Tanzania. Lancet 356:113-121

4. Thurnham Dl et al. (2000) Innate immunity, gut integrity, and vitamin A in Gambian and Indian infants. JID 182 [Suppl 1]:23-28

5. Jackson JB, Becker-Pergola $G$ et al. (2000) Identification of the $\mathrm{K} 103 \mathrm{~N}$ resistance mutation in Ugandan women receiving nevirapine to prevent HIV-1 vertical transmission. AIDS 14:F111F115

6. Association Francois-Xavier Bagnoud. Orphan Alert-international perspectives on children left behind by HIV/AIDS. Association Bagnoud, Paris

7. Chitnis A, Rawls D, Moore J (2000) Origin of HIV type 1 in colonial french equatorial Africa? AIDS Research and Human Retroviruses 16:5-8

8. Kasozi ABK. Linkage of conflict to the spread of HIV/AIDS in Uganda, 1980-1999. 13. Internationale AIDS-Konferenz, 8.-12.7.2000, Durban Südafrika

9. French N, Nakiyingi J et al. (2000) 23-valent pneumococcal polysaccharide vaccine in HIV1-infected Ugandan adults. Lancet 355:2106-2111

10. Spoulou V, Theodoriou M et al. (2000) Correspondence: 23 -valent pneumococcal vaccination and HIV. Lancet 356:1026-1036

11. Anglaret X, Chêne G et al. (1999) Early chemoprophylaxis with trimethoprim-sulphamethoxazole for HIV-1-infected adults in Abidjan, Cote d'Ivoire: a randomised trial. Lancet 353:1463-1468 